\title{
Pathways to marital and non-marital first birth: the role of his and her education
}

\author{
Alessandra Trimarchi and Jan Van Bavel ${ }^{*}$
}

\begin{abstract}
A key demographic trend of the past decades has been the increasing share of first births occurring outside marriage. In analysing the factors associated with this trend, scholars have tended to focus on the characteristics of only one of the parents, typically the mother. This study examines the pathways to parenthood from a couple's perspective, focusing on the role of educational pairings; i.e. the combination of his and her education. Using a multistate approach, we examine the connection between educational pairings and the occurrence of the first birth inside or outside marriage for 12 European countries. We find that the presence of at least one highly educated partner lowers the likelihood of a non-marital first birth. Strikingly, it does not matter whether it is he or she who has the highest level of education.
\end{abstract}

\section{Introduction}

For many Europeans, marriage is no longer a prerequisite for childbearing. Since the 1970s, rates of childbearing within cohabitation have been increasing in Europe (Sobotka and Toulemon 2008; Perelli-Harris et al. 2012). Although changes in family behaviour have not occurred to the same extent or at the same speed in all parts of the continent, these changes have at least two common features across European countries. First, non-marital childbearing has not spread homogenously, as differences between educational subgroups have been detected (Perelli-Harris et al. 2010). It has been shown that new family forms play a key role in the

\footnotetext{
* Alessandra Trimarchi (corresponding author), Institut National d'Études Démographiques (INED), Paris, France

Email: alessandra.trimarchi@ined.fr

Jan Van Bavel, Centre for Sociological Research/Family and Population Studies, Faculty of Social Sciences, University of Leuven, Belgium

Email: Jan.VanBavel@kuleuven.be
} 
reproduction of social inequalities, and have varying effects on children's well-being in different social strata (McLanahan and Percheski 2008). Second, within Europe, the increase in non-marital childbearing has been largely attributed to the rise of childbearing within cohabiting unions, rather than to single motherhood (Kiernan 2004; Perelli-Harris et al. 2010).

In studies about new family forms, scholars have focused mainly on the relationship between the mother's human capital and non-marital childbearing, and rarely on the link between human capital and non-marital fatherhood (Carlson et al. 2011; Perelli-Harris et al. 2010). Given that most non-marital births occur within co-residential unions, the decision to have a child usually involves two people; i.e. a couple. However, most scholars who have examined new family forms have disregarded the role of the partners' educational characteristics as determinants of non-marital childbearing, and have instead adopted an individualfemale perspective. While in recent years the male partner's role has increasingly been considered in studies as a potential determinant of the transition to parenthood (see, e.g. Begall 2013; Jalovaara and Miettinen 2013; Gustafsson and Worku 2006; Nitsche et al. 2015; Vignoli et al. 2012), empirical evidence on how the male partner's characteristics are related to non-marital family formation is still scarce (Trimarchi et al. forthcoming).

The couple's perspective is important because focusing on the features of only one partner may lead to a misinterpretation of the results (Gustafsson and Worku 2006). When scholars focus solely on the characteristics of the female partner, they are failing to consider the possibility that the effects of the educational level of one partner reflect the effects of the education of the other partner. As a result, if there are gender differences in the association between education and non-marital fertility, individual-level results would be inconclusive: negative and positive effects will cancel out, leading to a flat gradient. On the other hand, if the association between education and non-marital fertility is the same for both sexes, individuallevel studies will tend to overestimate or to underestimate the educational gradient. In both cases, depending on the prevalent educational mating pattern - i.e. the extent to which partners tend to sort homogamously or heterogamously according to their level of education - the bias could be more or less serious. Another reason to focus on the association between the education of both partners and non-marital childbearing is linked to the changing composition of mating markets. Individuals who face difficulties in finding a suitable partner may be inclined to settle for a less committed partnership; without, however, renouncing childbearing (Harknett 2008; Van Bavel 2012). For example, a highly educated woman may settle for a less educated partner, especially given the recent reversal of the gender gap in higher education (Van Bavel 2012).

Furthermore, considering both partners has implications at the societal level, because how partners combine their human capital - i.e. the educational pairing of his and her education - affects the reproduction of inequalities in societies. Educational assortative mating patterns reflect the degree of openness in a society, and affect the distribution of resources within it (Blossfeld 2009; Schwartz 2009). 
If men and women mate assortatively according to their socio-economic status, and if both men and women with lower levels of education have relatively high rates of cohabitation and unmarried parenthood, we would expect to see a concentration of these family behaviours among couples with fewer socio-economic resources. This trend would lead to an exacerbation of social inequalities in societies driven by changes in family forms.

In this paper, we aim to fill the gap in the literature on the educational gradient of non-marital childbearing by examining the link between educational pairing and the transition to the first child, while distinguishing between couples who married before the birth of their first child, and those who did not. How is the combined education of the partners associated with pathways to the first birth? A couple may make the transition to the first child without going through the transition to marriage. Alternatively, a couple may first marry and then have their first child. To investigate which of these pathways a given couple has followed, and how both his and her education are associated with the trajectory chosen, we apply multistate modelling. This kind of model is suitable for helping us gain an understanding of how differences in life histories are associated with specific background characteristics - e.g. the educational pairing of the couple - since these models are estimated using data that track occurrences of events and the units at risk for each event of interest (Willekens 2014). We used the retrospective fertility and partnership histories for 12 European countries recorded in the Generation and Gender Surveys (GGS) and in the Italian Family and Social Subjects (FSS) survey of 2009 .

\section{Inequalities, new family forms, and the role of educational assortative mating}

On a societal level, the diffusion of more liberal family behaviours - such as divorce, cohabitation, and non-marital childbearing - has often been interpreted as an expression of an ideational change in values and attitudes towards the family within the Second Demographic Transition (SDT) framework (Van de Kaa 1987; Surkyn and Lesthaeghe 2004). The SDT model posits that in societies in which cohabitation and non-marital childbearing are seen as antithetical to traditional family forms and life paths, these behaviours are considered, at least in an initial stage, prerogative behaviours of more secularised individuals, who are typically highly educated (Lesthaghe 2010; Surkyn and Lesthaeghe 2004).

Despite the steep increase in the level of non-marital fertility, at the individual level, marriage is still generally considered to be more conducive to childbearing than unmarried cohabitation (Baizan et al. 2003). There is evidence that partners view marriage as entailing a high level of commitment (Perelli et al. 2014). For men in particular, marriage is perceived as expressing a higher degree of commitment than unmarried cohabitation (Lehrer et al. 1996). Since married unions tend to be 
more stable than unmarried ones, married couples tend to have higher fertility as well (Lillard and Waite 1993; Lillard et al. 1995; Baizan et al. 2003).

In particular, scholars have been interested in analysing the educational gradient in non-marital childbearing and how it varies over time and across contexts. To understand how non-marital family formation is associated with educational differences, scholars have privileged an individual level of analysis. The focus has only recently shifted to couples' behaviour and the interaction between the partners' socio-economic characteristics, including his and her education (Van Bavel 2012; Trimarchi et al. forthcoming).

\subsection{Non-marital family formation and the role of educational level}

A strand of literature has emphasised the lack of socio-economic resources as a determinant in the choice of cohabiting rather than marrying when forming a new family (Perelli-Harris and Gerber 2011; Perelli-Harris et al. 2010). More specifically, many couples associate marriage with an expensive wedding ceremony, and with the requirement that they are able to secure their long-term economic independence (Kravdal 1999; Salvini and Vignoli 2014). Given these widespread perceptions, non-marital childbearing is expected to be more prevalent among the least educated. Perelli-Harris and Gerber (2011) have called this gradient the "pattern of disadvantage". If marriage is indeed becoming "a province of the most educated" (Goldstein and Kenney 2001, 506), the diffusion of cohabitation and non-marital childbearing among the less educated would exacerbate inequalities in society. If this trend continues, children born to highly educated women will enjoy a growing share of both social and economic resources, while children born to less educated women will be more likely to face the dissolution of their parents' union, and to live in poverty (McLanahan 2004; McLanahan and Percheski 2008).

Evidence supporting the "pattern of disadvantage" framework has been provided by a number of empirical studies conducted in different contexts. Perelli-Harris et al. (2010) found that among women in Austria, France, the Netherlands, Norway, Russia, the United Kingdom, and western Germany, the negative educational gradient in the transition to the first birth was steeper for non-marital births than for marital births. The analysis for Italy that compared the first non-marital birth to the first marital birth found a U-shaped educational gradient. The authors attributed these findings to the low prevalence of cohabitation, and argued that in contexts in which non-marital childbearing is just emerging, like in Italy, women with either low or high levels of education are more likely to have a child outside of marriage than their medium-educated counterparts. But in contexts in which cohabitation is common, less educated women are more likely to have a nonmarital child than women with medium or high levels of education. In France, the link between education and non-marital childbearing has changed over time: while highly educated women were driving the increase in non-marital childbearing during the 1970s and 1980s, the positive educational gradient disappeared around 
the start of the 21st century (Perelli-Harris et al. 2010). In Hungary (Spelder and Kamaras 2008) and the Czech Republic (Sobotka et al. 2008), the diffusion of nonmarital childbearing followed a bottom-up rather than a top-down pattern.

While the pattern of disadvantage framework mainly focuses on women's socio-economic conditions, Oppenheimer (2003) proposed a theoretical argument based on the relationship between men's socio-economic conditions and the rise of cohabitation. Men with poor and uncertain economic prospects may favour cohabitation as a union type because having low earnings and an unstable economic situation may undermine their ability to make a strong commitment (Oppenheimer 2003). Moreover, uncertainty on the labour market can affect the lifestyle men develop. Thus, men who experience career instability may face difficulties in finding a suitable partner, which would lead to delayed marriage. Most studies that have looked at this issue in European contexts have found that men with a relatively low socio-economic position are less likely to get married (Kalmijn 2011). Carlson et al. (2011) showed that this pattern of disadvantage is also applicable to US men. The authors found that non-marital fatherhood is negatively associated with education: the higher the man's level of education, the lower his risk of having a child outside marriage.

Given these earlier findings, and based on the economic argument that having more education provides men and women with more resources to get married, we formulate Hypothesis 1: There is a positive educational gradient in family formation through marriage. More specifically, Hypothesis la contends that there is a positive educational gradient in the transition from cohabitation to marriage. Hypothesis $1 \mathrm{~b}$ is concerned with the transition from cohabitation to parenthood: couples with more education are expected to have lower birth rates while they are still unmarried than couples with less education. The presence of at least one highly educated partner is expected to be associated with a reduced risk of non-marital childbearing.

\subsection{Non-marital family formation and the role of educational assortative mating}

The theoretical arguments mentioned so far have focused on the human capital of either women or men. More generally, most studies on fertility have adopted a female perspective rather than a couple's perspective, even though we know that most children are born to couples. An argument that has been used to justify the focus on just one of the partners is that people often mate with individuals who share similar characteristics (Corijn et al. 1996).

There is indeed evidence of a tendency to form homogamous partnerships based on several characteristics, such as age, ethnicity, religion, and education (Kalmijn 1991, 1994). Our focus here is on assortative mating by education, because education may affect individual economic potential, as well as individual tastes, preferences, and lifestyles (Blossfeld 2009). While educational homogamy remains the most common mating pattern in Europe (Blossfeld and Timm 2003; 
Hamplova 2009; De Hauw et al. 2017), marked changes in heterogamous couples have occurred. Recent studies have shown that unions in which the man is more educated than the woman (hypergamy) are now less common than unions in which the woman is more educated than the man (hypogamy) (Esteve et al. 2012; Grow and Van Bavel 2015; De Hauw et al. 2017).

With the reversal of the gender gap in education, there are more highly educated women than men reaching reproductive ages. Given the dearth of highly educated men, many highly educated women will not be able to mate homogamously. This implies that women who want to have children may be inclined to mate with a less educated partner in a less committed type of union, like unmarried cohabitation (Van Bavel 2012). Research from the United States has indeed argued that the type of union is associated with the type of educational match: "a different kind of relationship calls for a different kind of partner" (Schoen and Weinick 1993, 413).

Approaches that emphasise cultural aspects of educational assortative mating consider the match in lifestyles, values, and preferences (Blackwell and Lichter 2000). In the mate selection process, cohabitation is seen as the stage at which partners evaluate each other according to their "cultural matching". It appears that unmarried cohabiting couples are more likely than married couples to be in a heterogamous union, as unmarried cohabitation involves less commitment than marriage. In other words, partners who share more cultural traits will be more likely than partners who share fewer cultural traits to make the transition to marriage (Blackwell and Lichter 2000; Saarela and Finnäs 2014).

Thus, homogamous partners are expected to have more similar beliefs and lifestyles, which could lead them to strengthen their commitment by marrying (i.e. "cultural matching"). Based on this argument, we formulate Hypothesis 2: Homogamous partners are expected to have a higher transition rate from cohabitation to marriage than heterogamous couples.

By contrast, micro-economic theories regarding household formation emphasise the role of specialisation within the couple. According to Becker's theory of partner specialisation, spouses with dissimilar socio-economic resources gain more from marriage, because the partners increase their interdependence through the division of labour, which may be attached to gender roles (Becker 1991). Since educationally homogamous couples are less likely to specialise, these couples may be more inclined to live in a more "equal" union type such as cohabitation, whereas more specialised couples may gain more from a long-term committed union type such as marriage (Brines and Joyner 1999; Schoen and Weinick 1993). Following the specialisation argument, heterogamous couples cannot be considered homogeneous in their propensity for non-marital family formation.

We formulate three levels of comparison to highlight the differences between educational pairings with regard to the propensity for non-marital family formation. First, for the reasons explained above, educationally homogamous couples may have a higher propensity for non-marital family formation than heterogamous couples. Second, given that according to Becker's framework, the gains from marriage depend on the traditional gender division of labour, couples in which the man 
is more educated than the woman may be more inclined to marry because the difference in the economic potential of each of the partners increases the gains from marriage for both partners. Couples in which the woman is more educated than the man may be less inclined to marry.

Third, while both homogamous and hypogamous couples are expected to have a higher propensity for non-marital family formation than hypergamous couples, we expect to find that hypogamous couples are more likely than homogamous couples to have children outside marriage because their expected gains from marriage are smaller. This expectation is based on the assumption that couples tend to prefer a traditional gender division of labour. Thus, the gains are smaller for a woman because her male partner has a lower earning potential, and the gains are smaller for a man because his highly educated female partner may be less inclined to provide unpaid domestic work. As a result, the propensity for non-marital family formation of educationally homogamous couples is likely to be in between that of hypergamous couples, who have the lowest propensity for non-marital family formation; and of hypogamous couples, who are most likely to have children outside marriage.

Previous research that accounted for the characteristics of both partners, and of how these characteristics affect the transition to a marital or a non-marital birth, is scarce. Trimarchi et al. (forthcoming) found for Austria (cohorts 1970-1983) and for eastern Germany (cohorts 1971-1973 and 1981-1983) that when at least one of the partners in a couple is highly educated, the couple's risk of having a nonmarital rather than a marital birth is lower. But for western Germany, the authors found that hypergamous couples are less likely than other educational pairings to have a non-marital rather than a marital birth. Overall, the results showed that when studying non-marital childbearing, it is important to consider the educational levels of both partners, as well as the context. However, the authors examined the transition to the first child only, while disregarding the intermediate step; i.e. whether the couple made the transition to marriage. In this paper, we investigate a wider range of countries, and we account for the association between educational assortative mating and the transition to marriage, including for couples who have not (yet) had a first child.

In their study of several family transitions in Finland, Saarela and Finnäs (2014) found that compared to the homogamous couples, heterogamous couples face a higher risk of union dissolution, a higher risk of living in an unmarried union, and a lower risk of becoming parents. Moreover, they found that family formation within marriage is more common among the highly educated, whereas unmarried family formation is more common among the less educated (Saarela and Finnäs 2014). These results strongly suggest that an interaction between homogamy and the level of education affects the family formation behaviour of couples, and thus highlight the importance of taking the couple's perspective when studying fertility.

Based on these earlier findings as well as theoretical arguments, we formulate Hypothesis 3, which focuses on the differences in non-marital family formation behaviour within the group of heterogamous couples. We expect to find that 
hypergamous couples are more inclined towards traditional family behaviours, while hypogamous couples are more prone to display less conventional family behaviours, especially in countries with traditional gender roles expectations (i.e. Italy and Poland). This expectation stems from the Beckerian assumption that an education imbalance in favour of the male partner leads to a gendered division of labour, which in turn implies that both partners gain more from marriage. This hypothesis may be reinforced by socio-economic arguments that assert that if the partners in a couple have the same level of education, the man may have a higher earning potential than the woman. In particular, Hypothesis $3 a$ concerns the transition from cohabitation to marriage: we expect to find that hypergamous couples have a higher rate of marriage than hypogamous couples. As a complement, Hypothesis $3 b$ contends that hypergamous couples are more inclined than hypogamous couples to have their first child within marriage.

\section{Data}

We used the first wave of Generation and Gender Survey (GGS) data for 11 European countries (Austria, Belgium, Bulgaria, the Czech Republic, Estonia, France, Hungary, Lithuania, Poland, Norway, Romania) and the Family and Social Subjects (FSS) 2009 for Italy. Since the FSS is the Italian version of GGS, we preferred to use the most recent survey instead of the Italian GGS conducted in 2003. To acquire information on both partners' characteristics, we selected only individuals who were in a union at the time of the interview. For the GGS countries, the information is derived from both male and female respondents. For Italy, we could use female respondents only, since in the Italian GGS the male respondents are either the partners of the female respondents, or single men with no information about their previous partners' educational levels. We focused on the respondents and their partners who were born after 1950, because the changes in family behaviours that motivate our study occurred from the 1970s onwards. Thus, the affected cohorts were born in the 1950s or later. Considering the respondents born after 1950 also has methodological advantages, since according to Vergauwen et al. (2015), GGS data are suitable for studying fertility, especially for cohorts born after the mid-1940s and for periods after the mid-1970s. As our focus is on the transition to parenthood, we selected couples in which the woman was 15-45 years old at the beginning of the coresidential union, and we excluded cases in which one of the partners already had a child from another relationship (overall, we have 48,344 couples). Appendix A provides details on the number of cases that were and were not selected in our analytical sample for various reasons.

\subsection{The main explanatory variable: educational pairings}

Given the importance of the concept of assortative mating, social scientists have invested considerable effort in its measurement. At the macro level, scholars 
have been interested in measuring the propensity to marry partners with given characteristics using measures of attraction, which also account for the pool of potential mates (Schoen 1981). For studies that focus on the micro level, and on education in particular, the main concern has been how to include the indicator that would best account for both the effect of education and the effect of the educational differences between partners (Eeckhout et al. 2012).

Since the focus of this paper is on the micro level, we have defined our main explanatory variable as the combined educational attainment of the partners, in line with previous studies on the effect of educational assortative mating on demographic behaviour (see, e.g. Mäenpää and Jalovaara 2014). Collapsing the categories from the international standard classification of education (ISCED 1997), we grouped the individuals into three levels of attainment: low, medium, and high. The first group includes those individuals who completed primary plus lower secondary school (at least eight years of schooling, ISCED 0,1,2). The medium category consists of individuals who reached the upper-secondary or post-secondary level (ISCED 3, 4). Finally, the highly educated category is made up of individuals who earned a bachelor's/master's/PhD degree (ISCED 5, 6).

In our model, we used a compound measure of educational assortative mating that consists of three categories for homogamous couples in which the man and the woman have the same level of educational attainment ("both low" (1); "both medium" (2), "both high" (3)); two categories for hypergamous couples in which the man is highly educated and the woman has a medium or low level of education (4), and in which the man has a medium and the woman has a low level of education (5); and two categories for hypogamy in which the woman has a high and the man has a medium or low level of education (6), and in which the woman has a medium and the man has a low level of education (7). A separate category is assigned if the educational information for one of the partners is missing.

It should be noted that the educational pairing variable is not time-varying because we only had information about the graduation date of each respondent, and not about the partners' educational trajectories. Thus, our results may suffer of anticipatory bias, since the partners may have acquired their highest educational level after the event of interest occurred. This is a concern, especially with regard to the transition to parenthood: if individuals have a child before attaining their desired educational degree, being a parent may reduce their likelihood of achieving their educational goals (Kravdal and Rindfuss 2008). In Table 1, we show the proportions of respondents who acquired the level of education reported at the interview after co-residence and after each of our events of interest; i.e. marriage and first birth. In the majority of countries, between $11 \%$ and $29 \%$ of the respondents attained their current level of education after moving in with their partner. Italy and Norway are outliers: just $3 \%$ of respondents in Italy and almost $40 \%$ of respondents in Norway had not reached their current level of education before starting to cohabit. The shares of respondents who had obtained their current level of education after marrying were higher than $20 \%$ in Norway and in two Baltic countries; between 10\%-20\% in the Central Eastern European countries; and lower than 10\% in Austria, Belgium, 


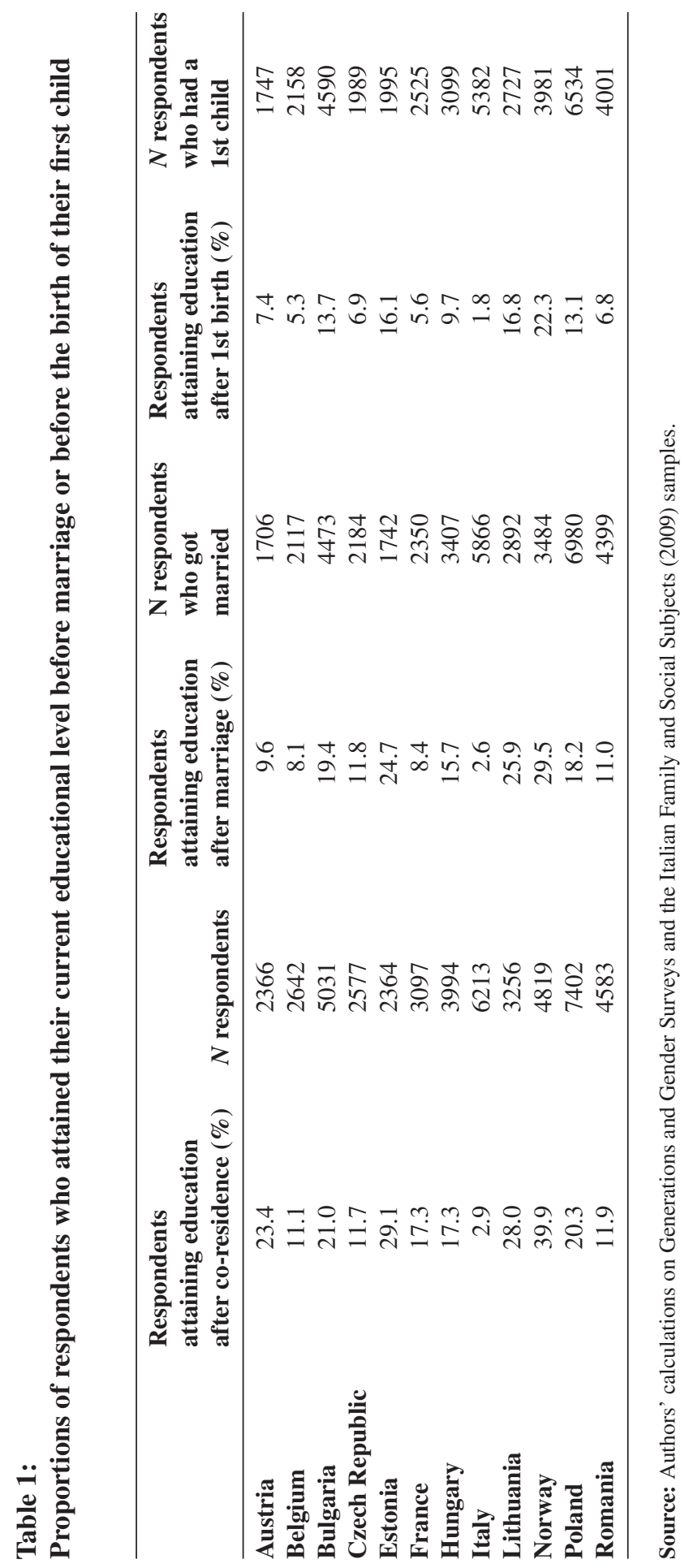


France, and Italy. These figures were even lower when we looked at the birth of the first child. In the majority of countries, less than $10 \%$ respondents who were parents had attained their highest level of education after the birth of their first child. The share of respondents who had a child before attaining their current level of education exceeded $20 \%$ only in Norway, where the educational system is highly flexible.

Table 2 shows the distribution of the educational assortative mating variable, as it has been employed in the models. Homogamous couples make up more than half of the couples in all of the countries studied. In the majority of homogamous couples, the partners are medium educated, except in Belgium and Italy. In Belgium, the largest share of the homogamous couples are highly educated $(32 \%)$; whereas in Italy, the largest share of the homogamous couples are less educated (30\%). While the most typical mating pattern is homogamy, it is interesting to look at the distribution of heterogamous couples. As we can see in Table 2, in the majority of countries, couples in which the woman is more educated than the man are more common than couples in which the man is more educated than his partner. This result is in line with recent trends in educational assortative mating that have been found across European and non-European countries (Esteve et al. 2012; Grow and Van Bavel 2015).

\subsection{Control variables}

We included the age difference between the partners in our models because it is an important determinant of a couple's fertility (Bhrolchain 1992; Bozon 1991). The age gap is operationalised in five categories: the age difference is zero or one year (which is considered age homogamy); the woman is older than the man; the man is two to four years older than the woman; the man is five or more years older than the woman; and a missing category if the age difference between the partners is not available. We also control for the respondent's sex, the woman's age at union formation and its square (in order to control for non-linearities), and the union's cohort (in four categories: 1967-1979 (1); 1980-1989 (2); 1990-1999 (3); 2000-2010 (4)). We added a control for the union order of the respondent only, since the union order of the partner is unavailable. Finally, we added a variable that specifies whether a conception occurred before marriage.

Table 3 shows the distribution of couples by country, according to their marital status at the time they started their co-residential union. The differences in the institutionalisation of cohabitation and its diffusion across Europe show up in a very simple way in Table 3 . In countries where cohabitation has spread relatively slowly and/or is not yet legally recognised, the majority of couples marry before they start co-residing. This pattern is found in the Central and Eastern European countries (i.e. Poland, Lithuania, Hungary, Romania, and, to a lesser extent, the Czech Republic) and Italy. In Austria, Belgium, Bulgaria, Estonia, France, and Norway, the majority of couples start co-residing while they are unmarried, and eventually marry. 


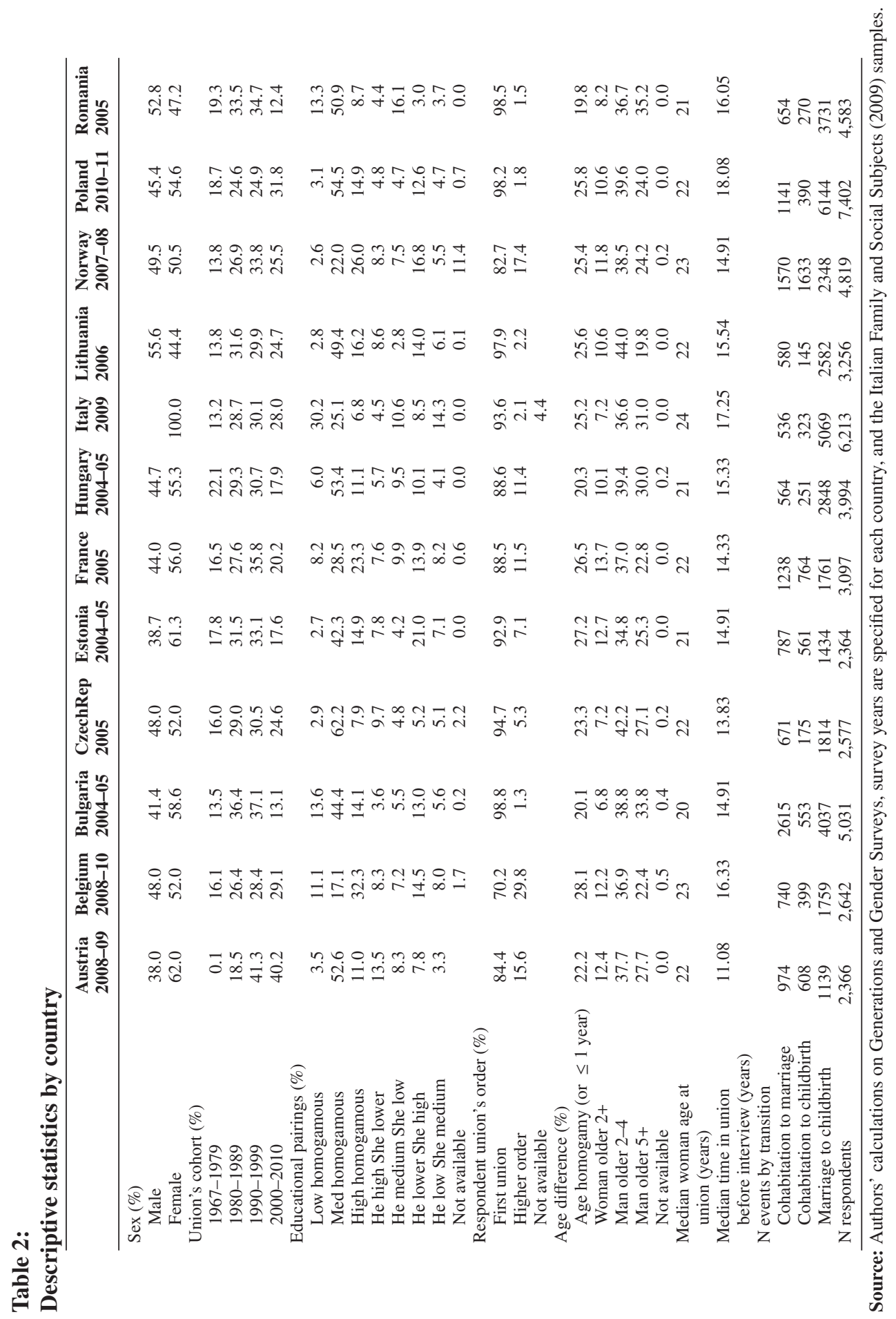


Table 3:

Distribution of couples by country and marital status at the time of union formation

\begin{tabular}{|c|c|c|c|c|c|c|}
\hline \multirow[b]{2}{*}{ Country } & \multicolumn{2}{|c|}{ Cohabitation first } & \multicolumn{2}{|c|}{ Direct marriage } & \multicolumn{2}{|c|}{ Total } \\
\hline & $(N)$ & $(\%)$ & $(N)$ & $(\%)$ & $(N)$ & $(\%)$ \\
\hline Austria & 1988 & 84.0 & 378 & 16.0 & 2366 & 100 \\
\hline Belgium & 1383 & 52.4 & 1259 & 47.7 & 2642 & 100 \\
\hline Bulgaria & 3363 & 66.9 & 1668 & 33.2 & 5031 & 100 \\
\hline Czech Republic & 1139 & 44.2 & 1438 & 55.8 & 2577 & 100 \\
\hline Estonia & 1610 & 68.1 & 754 & 31.9 & 2364 & 100 \\
\hline France & 2354 & 76.0 & 743 & 24.0 & 3097 & 100 \\
\hline Hungary & 1224 & 30.7 & 2770 & 69.4 & 3994 & 100 \\
\hline Italy & 1034 & 16.6 & 5179 & 83.4 & 6213 & 100 \\
\hline Lithuania & 996 & 30.6 & 2260 & 69.4 & 3256 & 100 \\
\hline Norway & 3808 & 79.0 & 1011 & 21.0 & 4819 & 100 \\
\hline Poland & 1796 & 24.3 & 5606 & 75.7 & 7402 & 100 \\
\hline Romania & 1008 & 22.0 & 3575 & 78.0 & 4583 & 100 \\
\hline Total & 21703 & 44.9 & 26641 & 55.1 & 48344 & 100 \\
\hline
\end{tabular}

Source: Authors' calculations on Generations and Gender Surveys and the Italian Family and Social Subjects (2009) samples.

\section{Method}

We applied multistate models to test our hypotheses regarding the effect of educational pairings on the chosen pathway to the first birth. The multistate approach can account for possible changes in the union status of each couple between the time they started to cohabit and the interview date. As we need information about both his and her education, we focus on respondents who were in a union at the time of the interview, since for most countries we know the education of the current partner only, not of earlier partners. This approach has advantages in terms of the quality of the reported fertility and partnership information (cf. Vergauwen et al. 2015), since people tend to better recall - and thus to report more accurately - events related to the present than to the past. It is, however, also a limitation, because couples who split up before the interview are left-censored. This implies that we may underestimate non-marital childbearing because cohabiting couples are more likely to split up (Kiernan 2004), and that hypogamous couples may be underrepresented in our study if they are less stable (as indicated by Blossfeld 2014; Jalovaara 2013; and Mäenpää and Jalovaara 2014; but not by Schwartz and Han 2014; Theunis et al. 2015).

We selected couples who were together at the time of the interview, and looked retrospectively at the changes in their union status leading up to their first shared birth, if it occurred. Unions that survived until the time of the interview may have been more stable on average than the total population of couples ever formed. 
Figure 1:

State-space considered and possible transitions

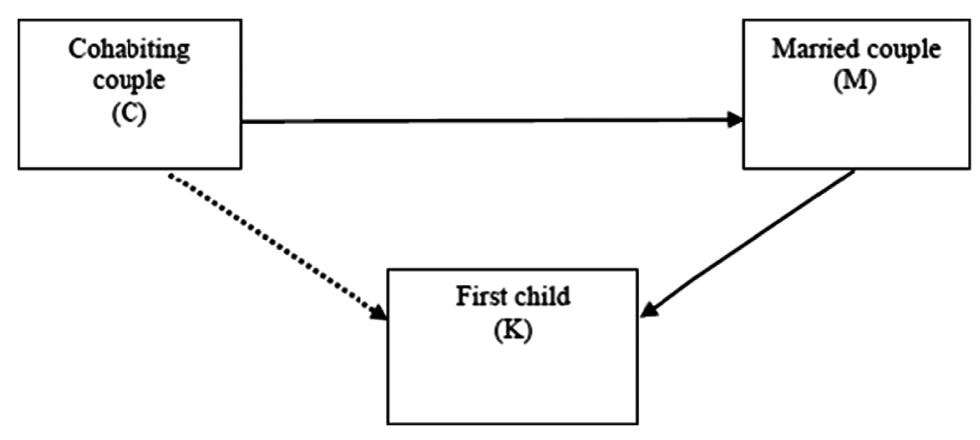

Obviously, unions formed in the years immediately before the interview may have been much more heterogeneous with regard to their stability (as they were not yet at risk of splitting up). To check how strongly this affected our results, we ran analyses for the recently formed unions (2000-2010) only, and found that our conclusions remained the same.

In this setup, our main event of interest is the birth of the first child, which represents the absorbing state in multistate terminology (Putter et al. 2007; Willekens 2014). Figure 1 shows all the possible transitions within our analytical state-space. At the start of the co-residential union, the partners may have been cohabiting (top left in Figure 1) or married (top right). After marriage, couples were at risk of only one transition; i.e. the transition to parenthood. Couples who started co-residence as an unmarried couple were at risk of two possible pathways. First, they may have married and had a child after marrying (Figure 1 - solid line). Second, they may have had a child within cohabitation (Figure 1 - dashed line). In the second case, a separate analysis is carried out to check which kinds of couples eventually married after having a non-marital birth. This model assumes a Markov process, which implies that the pathway of a couple and its timing depend on the present state only, and not on the event history of the couple.

Once we have all the transition dates, we expand the dataset for each possible transition that the couple may experience, defining the entry into and the exit from that state (or the end of the observational period), and a status variable that indicates whether the transition has occurred. As in Putter et al. (2007), we estimate the model by applying a Cox's proportional hazard model for each transition (i.e. stratified hazard model), separately country by country. Formally, the hazard for transition $i$ to $j$ for a couple with a covariate vector $\mathrm{Z}$ will be:

$$
\lambda_{i j}(t \mid \boldsymbol{Z})=\lambda_{i j, 0(t)} \exp \left(\beta_{i j}^{T} \boldsymbol{Z}\right)
$$

Where $\lambda_{i j, 0(t)}$ is the baseline hazard of transition $i$ to $j$ that is not parametrically specified, and $\beta_{i j}$ are the regression coefficients that describe the effect of the 
covariate profile of each couple. We have fitted the model by using the mstate package implemented in the $\mathrm{R}$ software (De Wreede et al. 2011). The regression coefficients are estimated via the maximum likelihood method, and we apply a stepwise modelling procedure to fit the best model. In order to evaluate the goodness of fit of the models, we used the likelihood-ratio test. The likelihood-ratio test shown in Table B.3 of Appendix B indicates the increase in the model fit after the educational pairing variable is included. We selected 12 countries that mirror the main family regimes in Europe, and rather than just pooling all countries, we replicated the analyses country by country to check how sensitive our main results are to the context. Given the small number of countries that could be included, we were not able to address the role played by contextual factors.

\section{Results}

Figures 2, 3, and 4 show the main results relative to the effect of educational pairing for all of the transitions considered (Appendix B gives all the model estimates). Each of these figures consists of a grid of panels, with the columns representing her educational attainment, the rows representing his educational attainment, and the lines representing 95\% confidence intervals of the point estimate. Each panel shows a specific combination of her and his educational levels to be compared with the reference category. The reference category is made up of the medium educated homogamous couples, and is represented by the horizontal line in each panel. On the diagonal of each figure are panels comparing the homogamous couples to the reference category (the panel in the middle of each figure does not give estimates, as this is the medium educated reference category). The panels above the diagonal show the results for the hypogamous couples, whereas the panels below the diagonal display the results for the hypergamous couples.

Figure 2 displays the hazard ratios for the transition from cohabitation to marriage. When we look at the diagonal, we see that in countries where the difference is significant, the less educated homogamous couples have lower rates of transition from cohabitation to marriage than the reference category of medium educated homogamous couples. Austria is a striking exception: the less educated homogamous couples are found to have a transition rate to marriage that is almost 2.5 times higher than that of the medium educated homogamous couples. Additional inspection of the data revealed that this finding is related to the low educational levels of migrant populations, who are much more likely to marry than cohabit. This result is also in line with previous research on Austria by Berghammer et al. (2014).

The findings for the heterogamous couples, which are shown above and below the diagonal, are not statistically different from those for the medium educated homogamous couples. However, when we switch the reference category to the less educated homogamous couples, we notice that the heterogamous couples with at least one highly educated partner tend to have higher rates of marriage than the less 
Figure 2:

Hazard ratios for the transition from cohabitation to marriage

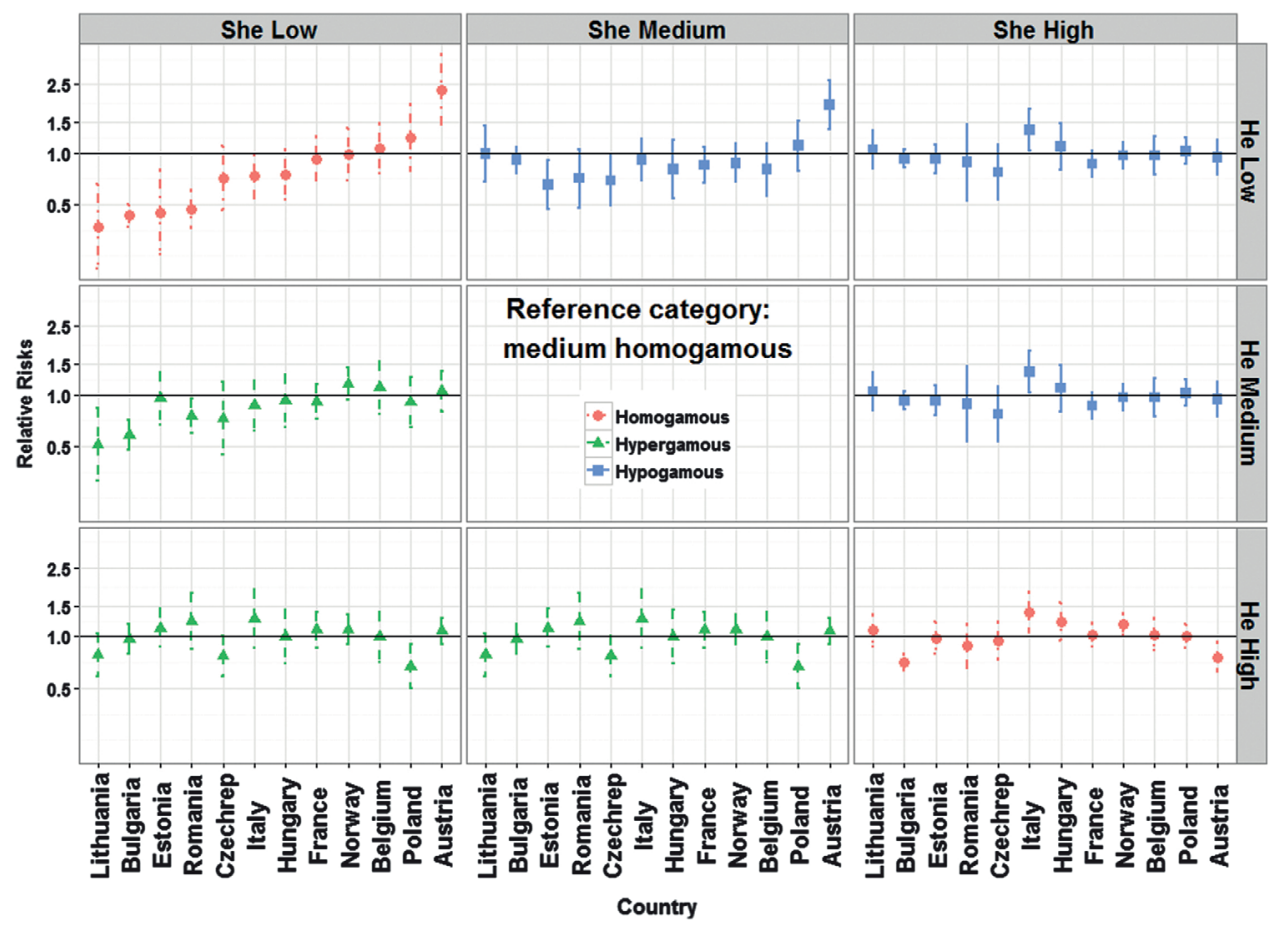

Source: Models' estimates (see Appendix B, Table B.1), GGS, and Italian FSS 2009.

educated homogamous couples (see Appendix C - Table C.1 for all the pairwise comparisons). This pattern is observed for Bulgaria, Estonia, Italy, Lithuania, and Romania; and it is in line with our expectations derived from the socio-economic Hypothesis la, which stated that there is a positive educational gradient in the transition from cohabitation to marriage.

Moreover, there is no evidence in support of the second hypothesis, which is concerned with the differences between homogamy and heterogamy. According to Hypothesis 2, we should find that homogamous partners have a higher transition rate from cohabitation to marriage than heterogamous couples. After comparing homogamous couples and heterogamous couples with all levels of education (see Figure 2 and Appendix C - Table C.1), we observed no significant differences in the transition rates from cohabitation to marriage. Thus, we found no empirical evidence for an effect of homogamy (or heterogamy) as such, separate from the role of the absolute level of education of the partners.

In general, the results for the transition from cohabitation to marriage support the socio-economic argument of the first hypothesis (1a); but not of hypothesis $3 a$, 
Figure 3:

Hazard ratios for the transition from cohabitation to the first birth

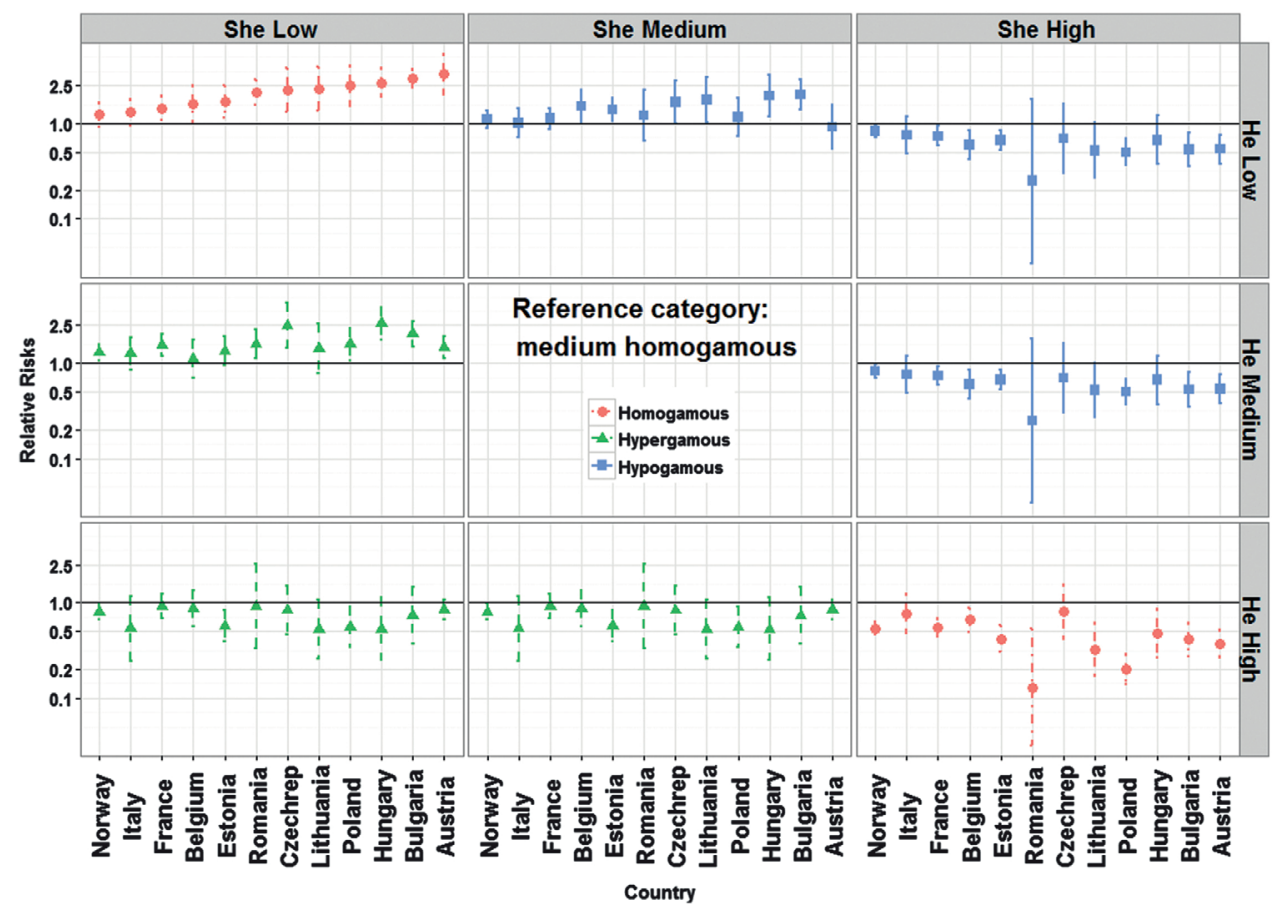

Source: Models' estimates (see Appendix B, Table B.2), GGS, and Italian FSS 2009.

which states that hypergamous couples have a higher rate of marriage than hypogamous couples. Still, we should highlight that in addition to Austria, two more countries deviate from this general pattern. First, in Bulgaria, highly educated homogamous couples have a lower transition rate to marriage than medium educated homogamous and heterogamous couples. It remains unclear why the presence of only one highly educated partner enhances the transition to marriage more than if the couple was composed of two highly educated partners.

Second, Poland also represents a puzzling exception. Here, couples in which the man is highly educated and the woman is less educated are found to have a lower transition rate to marriage than all the homogamous and the hypogamous educational pairings. Compared to the other countries considered, traditional values are more prevalent in Poland. Thus, the diffusion of cohabitation has been relatively slow in Poland, and the male breadwinner model continues to be the main family model, especially after the birth of the first child (Kotowska et al. 2008; Matysiak 2005). Nonetheless, this result contradicts our expectations that in traditional 
Figure 4:

Hazard ratios for the transition from marriage to the first birth

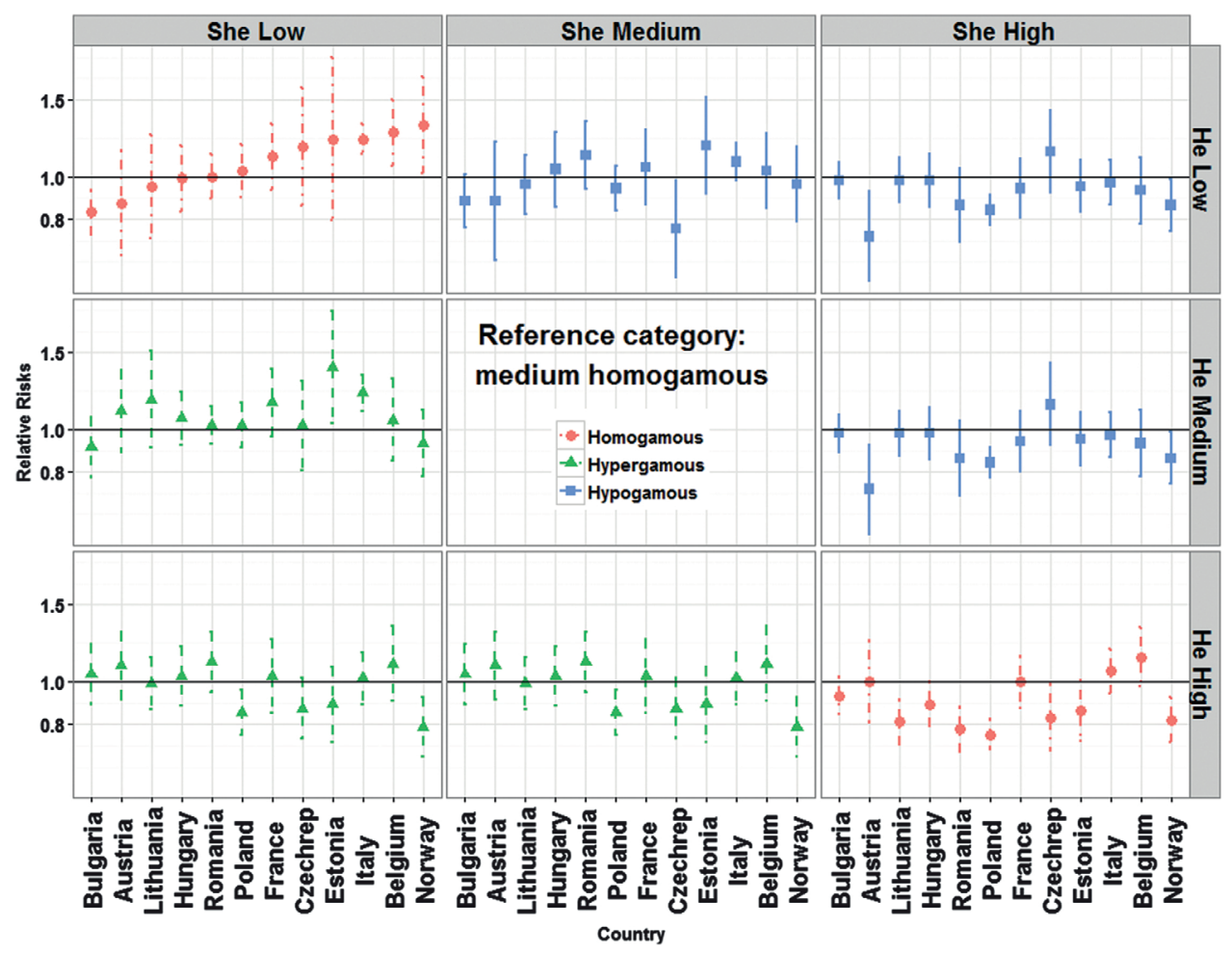

Source: Models' estimates (see Appendix B, Table B.3), GGS, and Italian FSS 2009.

contexts, hypergamous couples would be more prone to marriage than hypogamous couples (Hypothesis $3 a$ ).

Next, Figure 3 shows the hazard ratios for the transition from cohabitation to the first birth. In all countries, less educated homogamous couples have higher non-marital birth rates than medium educated couples, whereas highly educated unmarried couples exhibit lower non-marital birth rates (diagonal Figure 3). In general, there are no statistically significant differences between heterogamous couples and the reference category (medium educated homogamous couples). When we change our reference category to highly or less educated homogamous couples, the results strongly support the socio-economic resource argument; i.e. Hypothesis $1 b$, according to which the presence of at least one highly educated partner should reduce the risk of a non-marital birth (see Appendix C - Table C. 2 for all the pairwise comparisons). Across all countries, we find that the risk of non-marital family formation decreases as the overall human capital of the couple increases. This result is striking, because it implies that family formation behaviour 
does not differ depending on whether it is the male or the female partner who has more education. In both cases, the estimates point in the same direction.

Figure 4 shows the hazard ratios for the transition to parenthood after marriage. The pattern we see here is not as clear as the pattern we observed for the transition to a non-marital birth. The only exception is Norway, where we see a negative educational gradient in the transition to both a marital and a non-marital first birth; although the gradient is less pronounced in the latter case. Moreover, we find that in Italy, as in Norway, less educated homogamous couples have higher marital birth rates than all of the other educational pairings. In Italy, this gradient is much steeper than the gradient found for non-marital births. These results are in line with previous findings for Italy showing that compared to medium educated women, highly educated women have higher relative first birth risks in cohabitation than in marriage (Perelli-Harris et al. 2010). In Bulgaria, by contrast, less educated homogamous couples tend to have lower marital birth rates than medium educated homogamous couples and heterogamous couples with at least one highly educated partner (see Appendix C - Table C.3 for all the pairwise comparisons). In Austria and Romania, hypergamous couples in which the man is highly educated have higher marital childbearing rates than hypogamous couples in which the woman is highly educated. These results provide evidence in support of Hypothesis $3 b$, which states that couples in which the man is more educated than the woman are more prone to marital childbearing than couples in which the woman is more educated than the man. We also find no statistically significant difference between hypergamous and hypogamous couples in which the partner with the highest level of education is medium rather than highly educated. Moreover, when we compare the patterns in the transition to parenthood of married and unmarried cohabitating couples, we notice that in Austria, hypogamous couples in which the woman is highly educated have significantly lower birth rates overall than hypergamous couples in which the man is highly educated. This finding implies that at least in Austria, where the male breadwinner model has remained relatively strong (Prskawetz et al. 2008), hypogamous pairings are not conducive to childbearing, irrespective of whether the partners are married.

We briefly discuss the effects of two additional couple level variables: namely, the effect of the union's cohort and the age difference between the partners. As expected, we find that across European countries, the unions formed between 2000 2010 had lower transition rates to marriage than the unions formed in the 1990s (our reference category). On the other hand, the unions formed in the 1970s and the 1980s had higher transition rates from cohabitation to marriage than the reference category. This cohort effect probably emerged because, ceteris paribus, unmarried cohabitation became more socially accepted over time, and individuals who had spent more time as an unmarried couple were feeling less pressure to get married. We ran the same models by censoring the observation time after five or 10 years since the co-residential union was formed, and the results were robust. We also failed to find a strong effect for the age difference between partners. In other contexts as well, the age difference between the partners in a cohabiting union was not found 
to have a significant effect on fertility (cf. Wu 1996). The age difference between the partners appears to matter most for the transition from cohabitation to marriage, as couples in which the man is older than the woman are found to have higher transition rates to marriage than couples in which the partners are similar in age. This finding is in line with Hypothesis $3 a$, which states that more traditional couples are more prone to marriage than other pairings. However, this pattern applies only to the transition from cohabitation to marriage, as the effect of the age difference is not found to be significant for childbearing.

\section{Discussion: The beaten path to parenthood}

In recent decades, an important focus of family demographic studies has been the determinants of non-marital childbearing. However, scholars have tended to emphasise the association between socio-economic resources and the risk of having a non-marital birth for women, while largely neglecting the characteristics of men. The results of analyses that considered the characteristics of one partner only, even though marital and non-marital births typically occur within a union, could therefore be misleading.

In this study, we examined for 12 European countries whether and how the type of educational pairing - i.e. how his and her education combine - affects the likelihood of having a first birth within marriage and within cohabitation. We investigated whether there is an effect of educational assortative mating that goes beyond the role of the absolute level of education, which has been previously studied. We observed couples who are in a co-residential union, and examined their pathways to parenthood using multistate modelling.

Overall, we found the most support for our general first hypothesis, which states that a higher level of human capital is associated with a lower likelihood of nonmarital family formation. This hypothesis is based on the argument that educational resources, which are seen as an indicator of an individual's long-term economic prospects, may be perceived as prerequisites for marriage. Our results show that couples with lower levels of human capital tend to stay in an unmarried relationship longer than their counterparts with higher levels of human capital (Hypothesis 1a). Couples with lower levels of human capital also tend to have higher transition rates to a non-marital first birth in most of the countries considered. The presence of at least one highly educated partner - regardless of whether the partner is male or female - is associated with a lower rate of non-marital first childbearing (Hypothesis $1 b$ ). Moreover, the results of additional analyses suggest that having more education is positively associated with marriage even after the birth of a first non-marital child (results not shown).

In line with previous findings, we found no support for our second hypothesis, which states that in addition to each partner's level of education, the degree of homogamy affects the transition to marriage. According to this hypothesis, homogamous couples are more inclined to marry than heterogamous couples 
(cf. Blackwell and Lichter 2000). We found that the behaviour of educationally homogamous couples is not statistically different from that of educationally heterogamous couples, and that the transition to marriage instead depends primarily on the overall human capital of the couple. Bulgaria is an interesting exception to this pattern: there, we found that couples in which the partners have different levels of education have higher marriage rates than highly educated homogamous couples, who are less likely to marry. This result contradicts both our first and second hypotheses. It contradicts Hypothesis $1 a$ because we expected to find that a higher level of human capital enhances the transition to marriage; and this was not shown to be the case in Bulgaria. Furthermore, it contradicts our second hypothesis regarding the role of homogamy in marriage. Our findings indicate that in Bulgaria, heterogamous couples with at least one highly educated partner are more inclined to marry than homogamous couples. We can speculate that this pattern is attributable to the advantages derived from a specialisation model à la Becker, which is characterised by unequal but complementary socio-economic resources within couples, but which in this case is not attached to traditional gender roles (Becker 1991; Schoen and Weinick 1993; Brines and Joyner 1999).

We also found no evidence supporting our third general hypothesis, which focuses on the differences in the effects of his versus her education. Based on the Beckerian specialisation model, we hypothesised that for at least two reasons, hypergamous couples are more inclined towards marital family formation than hypogamous couples. First, couples in which the man has more education than the woman may reinforce traditional behaviours driven by the imbalance of socioeconomic resources in favour of the man. Second, such couples may be more economically advantaged because, ceteris paribus, men earn more on average than women. Our results show that in most countries, there is no statistically significant difference in the pathways to the first birth among hypergamous and hypogamous couples. Poland represents an exception: hypergamous couples in which the man is highly educated have lower transition rates to marriage than hypogamous couples and all the other homogamous educational pairings. These results contradict Hypothesis $3 a$. Other studies on Poland have shown that unmarried cohabiting couples are most likely to be unemployed people or young people still enrolled in education who are supported economically by their parents (Kotowska et al. 2008; Matysiak 2009). This may help to explain our findings, as an additional data inspection revealed that most of these couples consist of young people who had not completed their education before starting to co-reside.

We should mention a number of limitations of this study. First, it is worth recalling that in order to answer our research question, we limited our study to individuals who were in a union at the time of the interview. By applying a multistate framework, we could account for the selective exit from cohabitation via marriage of the "surviving" unions, but we could not empirically test the role of divorce or separation. We could not disentangle whether the commitment is manifested via marriage or via childbearing, because in our sample, the more stable couples, among whom childbearing is more likely, are overrepresented. In the future, 
it would be interesting to examine how educational assortative mating varies across union type, and its interactions with union dissolution and childbearing. It may be the case that we underestimated the differential role of the partners' education in our study, which has been cancelled out by our focus on couples for whom childbearing is more likely. Moreover, the extent to which the selectivity of the sample may have altered the results also depends on the country. In particular, the results may be especially biased for those countries where there is a strong association between educational pairing and union dissolution rates. For instance, a previous study that looked at cohabiting unions formed between 1995-2002 in Finland found that unions in which the woman is more educated than the man were more likely to dissolve (Mäenpää and Jalovaara 2014). However, other studies have shown that this pattern may not hold for marital unions formed after the 1990s (cf. Schwartz and Han 2014 for the United States; Theunis et al. 2015 for Belgium). In order to check the sensitivity of our results to this selection, we ran analyses only for unions formed between 2000-2010, and found that our conclusions remain the same. Moreover, since we have information about the previous partners' education for five countries (Austria, Bulgaria, the Czech Republic, Estonia, and Poland), we checked how different the samples are for these countries when dissolved unions are also considered. We found that the distribution of educational pairings remained very similar in the two samples; and that despite the selection, the smaller sample included a substantial proportion of the events that were also present in the bigger sample (results available upon request).

Our results further indicate that in the more stable unions, the difference in the partners' educational levels has little effect on whether they have a marital or a non-marital birth; and that it is the partners' absolute levels of education that matter instead. Still, future studies should test whether accounting for the selective exit from cohabitation or marriage via union dissolution affects the role of educational pairings on fertility behaviour. This could be achieved by using longitudinal country-specific data, which have detailed information on the timing of the formation and dissolution of partnerships.

It is also possible that we were unable to grasp the role of educational heterogamy because of measurement issues. Since heterogamy is less common than homogamy, we could not consider all of the possible pairings of partners' educational levels because some of the categories were small. By using a compound measure of educational pairing that does not consider all of the possible combinations, we may have overlooked the role of heterogamy. The absence of a statistically significant effect of heterogamy could be due to large standard errors. An obvious solution to this problem is to use larger datasets. Alternatively, it may be possible to use a diagonal reference model, which offers an approach to analysing dyads that is more parsimonious and easier to interpret (cf. Eeckhout et al. 2012). However, diagonal reference models have not yet been implemented in combination with survival analysis. We should mention another potential measurement issue as well, namely, that we were unable to include a time-varying covariate of educational pairing because of lack of information. Our results may suffer from anticipatory 
bias, since the partners may have reached their highest level of education after they started to co-reside. The use of more detailed data that include the full educational histories of both partners could help to avoid anticipatory bias when applying eventhistory analysis (Hoem and Kreyenfeld 2006).

Finally, it is worth remembering that the estimates of the multistate model for the transition to the first birth within each union context may still reflect the overall educational gradient in childbearing of the country and cohorts considered. An overall negative educational gradient in the transition to parenthood is usually linked to the tendency among the more educated to postpone the birth of their first child. Our results show that the negative educational gradient in the transition to the first birth tends to be steeper within cohabitation than within marriage. It will be interesting to see whether this pattern continues in the future, given that in some countries (e.g. Belgium, France, Norway) changes over time have been detected: especially for the cohorts born in the 1960s or later, the overall negative educational gradient is weakening or even turning positive (Kravdal and Rindfuss 2008; Goldscheider et al. 2015).

Despite these limitations, our study yields insights into how educational pairings are associated with pathways to parenthood. We showed that it is important to also consider the effect of the male partner's education, as it can counterbalance the effect of the woman's education. In our study, we find support for the "pattern of disadvantage" framework, which usually refers to non-marital childbearing. More educated couples do not necessarily avoid cohabitation altogether, but they are more likely to get married if they are planning to have or expecting a child, or if they have had a child. Our results highlight that like in the United States, the diffusion of non-marital childbearing among the lower social strata in Europe may lead a widening of social inequalities. Future studies could focus on children's well-being to assess whether and to what extent a lack of human capital among unmarried parents translates into disadvantages for the children. It is plausible to expect that in more "open" societies, where individuals face fewer constraints in partnering with people of a different socio-economic status, the consequences for children born to unmarried parents will be offset in the longer term.

As we mentioned above, we found that the effects of homogamy did not differ from the effects of heterogamy. This could be because in contexts where the majority of people have a high level of education, homogamy in lifestyles and values may not necessarily be linked to the level of education. It is possible that educational assortative mating patterns linked to a specific field of study or occupation are more informative about how lifestyles affect the propensity for non-marital formation.

Interestingly, the evidence in support of hypotheses based on socio-economic arguments was more consistent across the different countries. By contrast, hypotheses based on the role of educational assortative mating lacked strong empirical support, as no clear patterns were found across countries. To uncover the mechanisms that link the mate selection processes to fertility, micro- and macrolevel studies should be integrated. It would be interesting to investigate the question of whether a higher degree of heterogamy within a country - i.e. whether a society 
is more "open" - is associated with higher levels of non-marital childbearing. A higher degree of heterogamy implies that the more educated people increasingly mate with less educated partners. The partners of less educated individuals who may be considered less attractive on the mating market could be inclined to settle for a less committed partnership without renouncing childbearing. In particular, as some authors have pointed out, this may be the case for highly educated women, given the recent changes in the education-specific mating markets (Harknett 2008; Van Bavel 2012). Thus, the distribution of non-marital childbearing among different social strata may be affected by the changing composition of mating markets.

\section{Acknowledgements}

This work has been carried out while the first author was employed at the Centre for Sociological Research of the University of Leuven in Belgium. The research leading to these results has received funding from the European Research Council under the European Union's Seventh Framework Program (FP/2007-2013)/ERC Grant Agreement no. 312290 for the GENDERBALL project (2013-2017).

\section{References}

Becker, G. S. 1991. A treatise on the family. Cambridge, MA: Harvard University Press.

Begall, K. 2013. How do educational and occupational resources relate to the timing of family formation? A couple analysis of the Netherlands. Demographic Research 29(October): 907-936.

Berghammer, C., K. Fliegenschnee and E.-M. Schmidt 2014. Cohabitation and marriage in Austria. Demographic Research 31(November): 1137-1166.

Blackwell, D. L. and D. T. Lichter 2000. Mate selection among married and cohabiting couples. Journal of Family Issues 21: 275-302.

Blossfeld, H. and A. Timm 2003. Assortative mating in cross-national comparison: A summary of results and conclusions. Who Marries Whom? 1981: 331-342.

Blossfeld, H.-P. 2009. Educational assortative marriage in comparative perspective. Annual Review of Sociology 35(1): 513-530.

Blossfeld, G. J. 2014. Educational assortative mating and divorce: A longitudinal analysis of the influences of education on the divorce rate for different educational matches. Paper presented at the Annual Meeting of the Population Association of America, Boston, 2014.

Brines, J., and K. Joyner 1999. The ties that bind: Principles of cohesion in cohabitation and marriage. American Sociological Review 64: 333-355.

Carlson, M. J., A. G. VanOrman and N. V. Pilkauskas 2013. Examining the antecedents of U.S. nonmarital fatherhood. Demography 50(4): 1421-1447.

Corijn, M., A. Liefbroer and J. de J. Gierveld 1996. It takes two to tango, doesn't it? The influence of couple characteristics on the timing of the birth of the first child. Journal of Marriage and the Family 58(1): 117-126. 
De Hauw, Y., A. Grow and J. Van Bavel 2017. The reversed gender gap in education and assortative mating in Europe. European Journal of Population 33: 445-474.

De Wreede, L. C., M. Fiocco and H. Putter 2011. mstate: An R package for the analysis of competing risks and multi-state models. Journal of statistical software 38(7): 1-30.

Eeckhaut, M. C. W., B. Van de Putte, J. R. M. Gerris and A. A. Vermulst 2011. Analysing the effect of educational differences between partners: A methodological/theoretical comparison. European Sociological Review 29(1): 60-73.

Esteve, A., J. García-Román and I. Permanyer 2012. The gender-gap reversal in education and its effect on union formation: The end of hypergamy? Population and Development Review 38: 535-546.

Goldscheider, F., E. Bernhardt and T. Lappegård 2015. The gender revolution: A framework for understanding changing family and demographic behavior. Population and Development Review 41(2): 207-239.

Grow, A. and J. Van Bavel 2015. Assortative mating and the reversal of gender inequality in education in Europe - An agent-based model. PLoS ONE 106: e01.

Gustafsson, S. and S. Worku 2006. Assortative mating by education and postponement of couple formation and first birth in Britain and Sweden. In Education and postponement of maternity. Economic analysis for industrialized countries, eds S. Gustafsson and A. Kalwij, 259-284. Dordrecht: Kluwer.

Hamplova, D. 2008. Educational homogamy among married and unmarried couples in Europe: Does context matter? Journal of Family Issues 30(1): 28-52.

Harknett, K. 2008. Mate availability and unmarried parent relationships. Demography 453: $555-571$.

Jalovaara, M. 2013. Socioeconomic resources and the dissolution of cohabitations and marriages. European Journal of Population 29: 167-193.

Jalovaara, M. and A. Miettinen 2013. Does his paycheck also matter? Demographic Research 28(April): 881-916.

Kalmijn, M. 1991. Shifting boundaries: Trends in religious and educational homogamy. American Sociological Review 56(6): 786-800.

Kalmijn, M. 1994. Assortative mating by cultural and economic occupational status. American Journal of Sociology 100(2): 422-452.

Kalmijn, M. 2011. The influence of men's income and employment on marriage and cohabitation: Testing Oppenheimer's theory in Europe. European Journal of Population 27(3): 269-293.

Kiernan, K. 2004. Unmarried cohabitation and parenthood in Britain and Europe. Law and Policy 26(1): 33-55.

Kravdal, Ø. 1999. Does marriage require a stronger economic underpinning than informal cohabitation? Population Studies 53(1): 63-80.

Kravdal, $\varnothing$. and R. Rindfuss 2008. Changing relationships between education and fertility: A study of women and men born 1940 to 1964. American Sociological Review 73(5): 854-873.

Lehrer, E. L., S. Grossbard-Shechtman and J. W. Leasure 1996. Comment on "a theory of the value of children". Demography 33(1): 133-139. 
Lillard, L. a and L. J. Waite 1993. A joint model of marital childbearing and marital disruption. Demography 30(4): 653-681.

Lillard, L. a, M. J. Brien and L. J. Waite 1995. Premarital cohabitation and subsequent marital dissolution: A matter of self-selection? Demography 32(3): 437-457.

Mäenpää, E. and M. Jalovaara 2014. Homogamy in socio-economic background and education, and the dissolution of cohabiting unions. Demographic Research 30(June): 1769-1792.

Matysiak, A. 2005. The sharing of professional and household duties between Polish couples: Preferences and actual choices. Studia Demograficzne 1: 122-154.

Matysiak, A. 2009. Is Poland really 'immune' to the spread of cohabitation? Demographic Research 218: 216-234.

McLanahan, S. 2004. Diverging destinies: How children are faring under the second demographic transition. Demography 41(4): 607-627.

McLanahan, S. and C. Percheski 2008. Family structure and the reproduction of inequalities. Annual Review of Sociology 34(1): 257-276.

Nitsche, N., A. Matysiak, J. Van Bavel and D. Vignoli 2015. Partners' educational pairings and fertility across Europe. FamiliesAndSocieties Working Paper Series 382015. Stockholm/Brussels: FamiliesAndSocieties/EU.

Oppenheimer, V. K. 2003. Cohabiting and marriage during young men's career-development process. Demography 40(1): 127-149.

Perelli-Harris, B. and T. P. Gerber 2011. Nonmarital childbearing in Russia: Second demographic transition or pattern of disadvantage? Demography 48(1): 317-342.

Perelli-Harris, B., W. Sigle-Rushton, M. Kreyenfeld, T. Lappegård, R. Keizer and C. Berghammer 2010. The educational gradient of childbearing within cohabitation in Europe. Population and Development Review 36(4): 775-801.

Perelli-Harris, B., A. Berrington, C. Berghammer, R. Keizer, T. Lappegård, M. Mynarska and D. Vignoli 2014. Towards a new understanding of cohabitation. Demographic Research 31(November): 1043-1078.

Perelli-Harris, B., M. Kreyenfeld, W. Sigle-Rushton, R. Keizer, T. Lappegård, A. Jasilioniene and P. Di Giulio 2012. Changes in union status during the transition to parenthood in eleven European countries, 1970s to early 2000s. Population Studies 66(2): 167-182.

Putter, H., M. Fiocco and R. B. Geskus 2007. Tutorial in biostatistics: Competing risks and multi-state models. 2389-2430.

Saarela, J. and F. Finnäs 2014. Transitions within and from first unions: Educational effects in an extended winnowing model. Marriage and Family Review 50(1): 35-54.

Schoen, R. 1981. The harmonic mean as the basis of a realistic two-sex marriage model. Demography 18(2): 201-216.

Schoen, R. and R. M. Weinick 1993. Partner choice in marriages and cohabitations. Journal of Marriage and the Family 55: 408-414.

Schwartz, C. R. 2009. Assortative mating. In Encyclopedia of human relationships, 123-125. Thousand Oaks, CA: Sage.

Schwartz, C. R. 2010. Pathways to educational homogamy in marital and cohabiting unions. Demography 47: 735-753. 
Sobotka, T. and L. Toulemon 2008. Overview Chapter 4: Changing family and partnership behaviour. Demographic Research 19: 85-138.

Sobotka, T., A. Št' Astná, K. Zeman, D. Hamplová and V. Kantorová 2008. Czech Republic: A rapid transformation of fertility and family behaviour after the collapse of state socialism. Demographic Research 19: 403-454.

Spéder, Z. and F. Kamarás 2008. Hungary: Secular fertility decline with distinct period fluctuations. Demographic Research 19: 599-664.

Surkyn, J. and R. Lesthaeghe 2004. Value orientations and the second demographic transition SDT in Northern, Western and Southern Europe: An update. Demographic Research, Special 3(April): 45-86.

Theunis, L., C. Schnor, D. Willaert and J. Van Bavel 2015. Educational assortative mating and marital stability: Adding a contextual dimension. Paper presented at the Annual Meeting of the Population Association of America, San Diego (CA).

Thomson, E. 1997. Couple childbearing desires, intentions, and births. Demography 34(3): 343-354.

Trimarchi, A., C. Schnor and J. Van Bavel forthcoming. Educational assortative mating and nonmarital childbearing within cohabitation-Evidence from four European contexts. In Partnership relations from adolescence to adulthood. Psychological and sociological perspectives, eds S. Walper, E.-V. Wendt and F. Schmahl. Springer.

Van Bavel, Jan. 2012. The reversal of gender inequality in education, union formation, and fertility in Europe. Vienna Yearbook of Population Research 10: 127-154.

Van De Kaa, D. J. 1987. Europe's second demographic transition. Population Bulletin 42(1): $1-59$.

Vergauwen, J., J. Wood, D. De Wachter and K. Neels 2015. Quality of demographic data in GGS Wave 1. Demographic Research 32(March): 723-774.

Vignoli, D., S. Drefahl and G. De Santis 2012. Whose job instability affects the likelihood of becoming a parent in Italy? A tale of two partners. Demographic Research 26: 41-62.

Willekens, F. 2014. Multistate analysis of life histories with R. Switzerland: Springer International Publishing. 


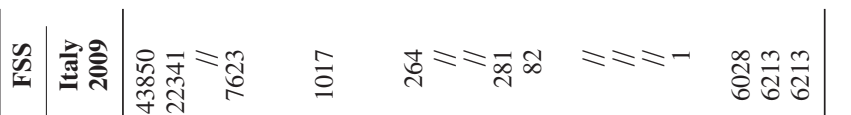

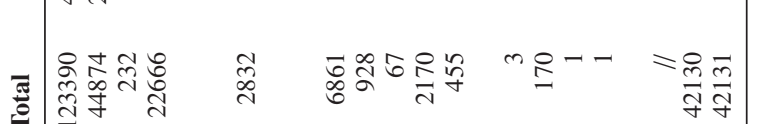

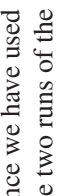

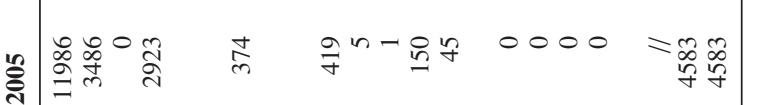

结

(

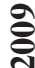

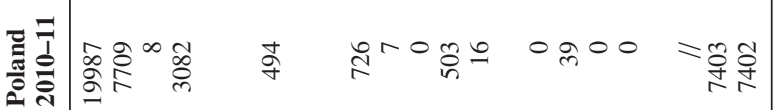

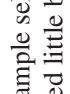

蛋

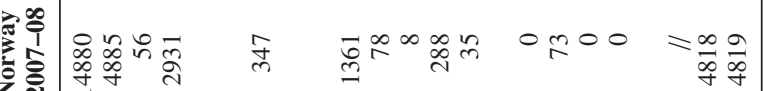

$\sigma$

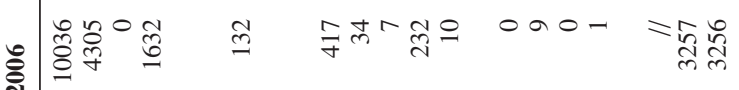

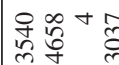

के

in

n-7

0700

जूूे

言空

突응

要

$3 \sum^{2} \div$

c

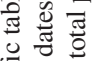

氜

Ð

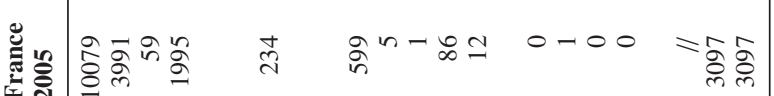

क्षे?

焉学

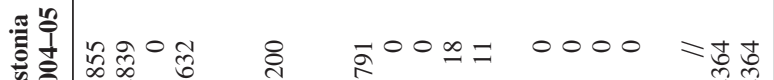

.

竞密

类

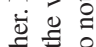

苟

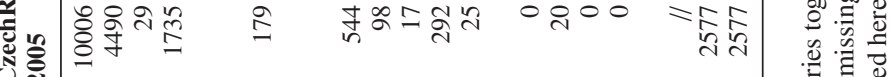

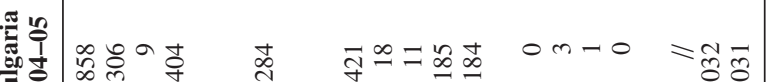

具要要

㭶范

记造营

๓⿴囗十

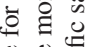

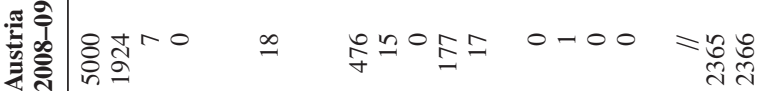

要焉

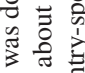

年

ธี.

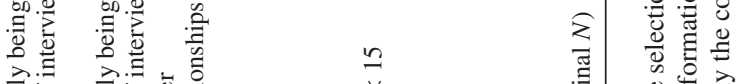

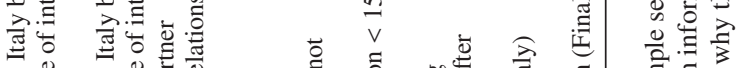

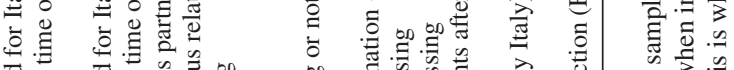

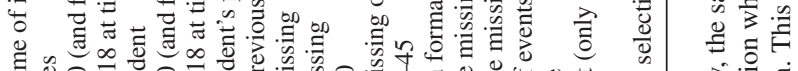

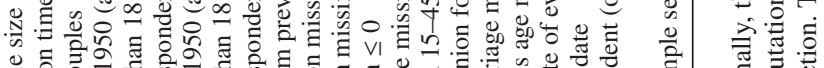

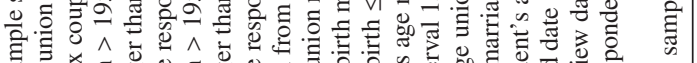

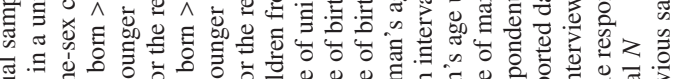

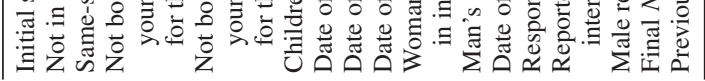

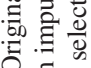

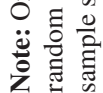




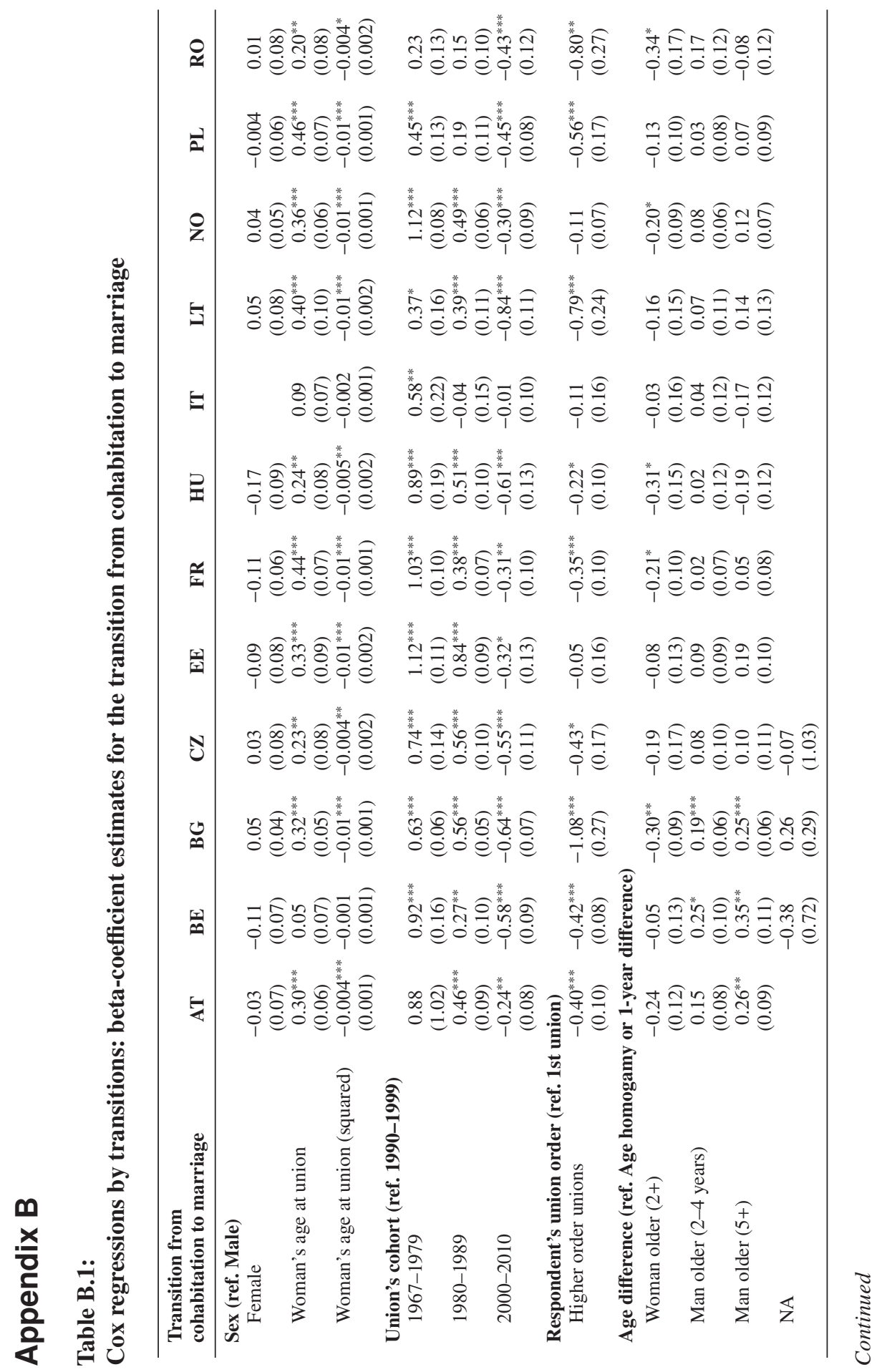




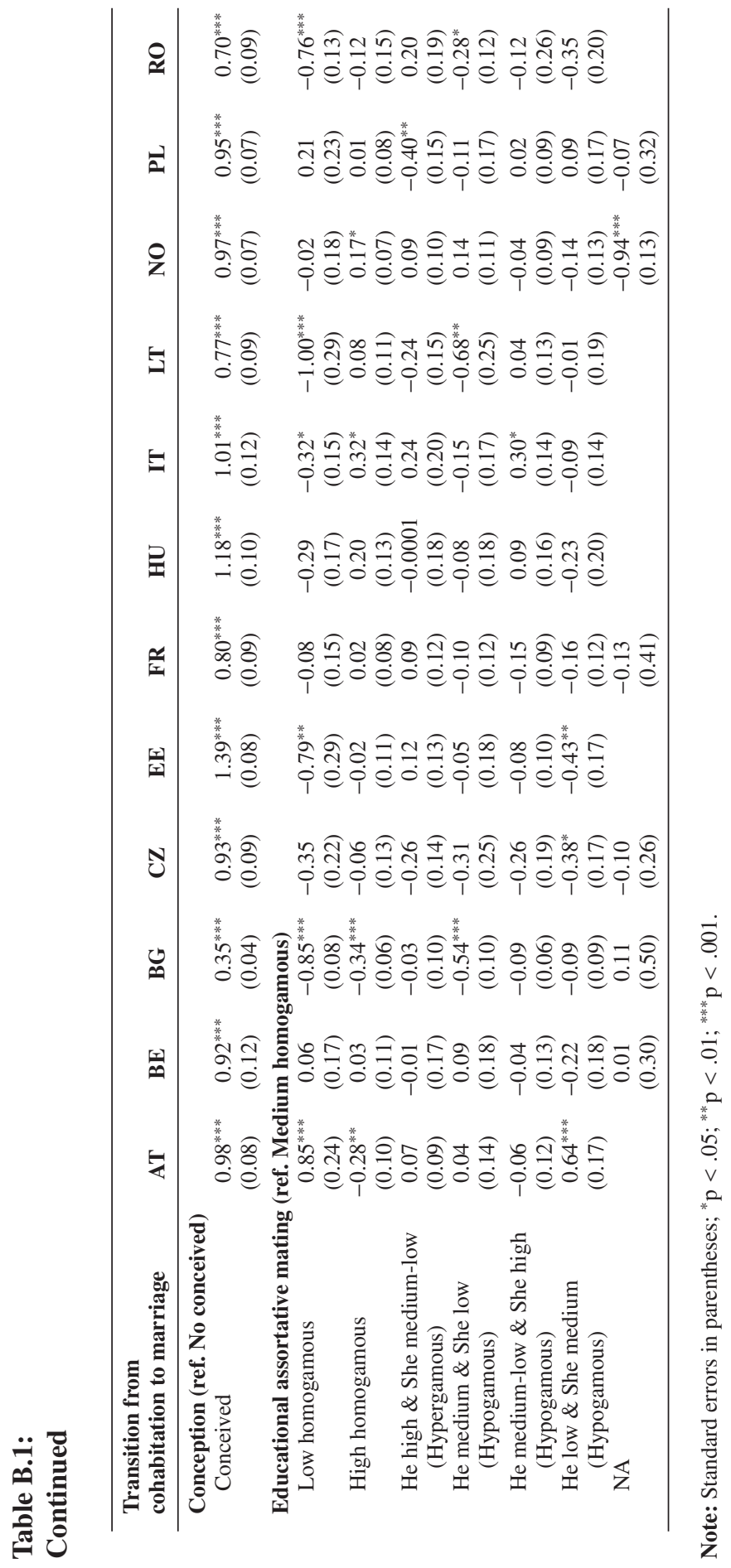




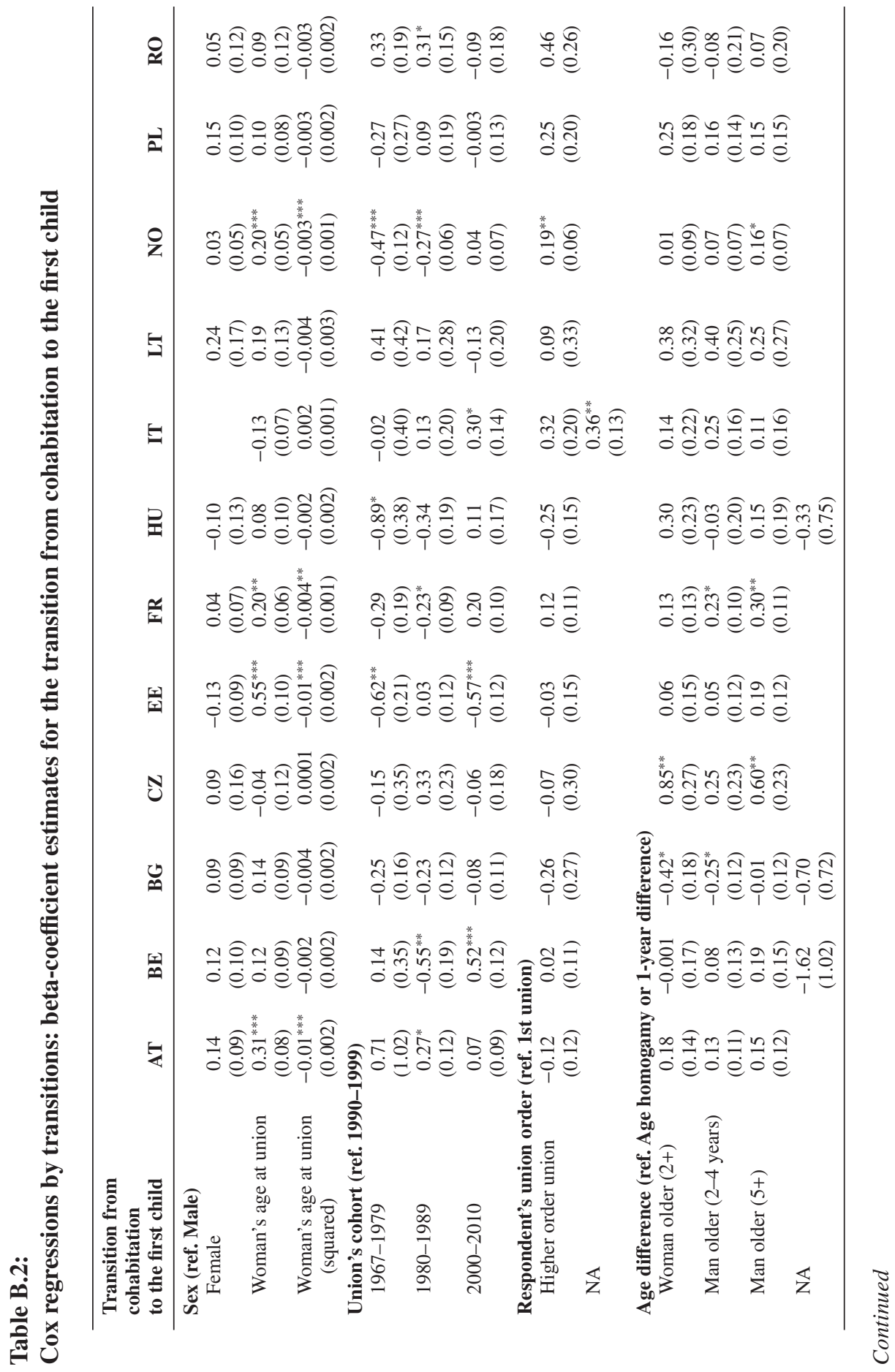




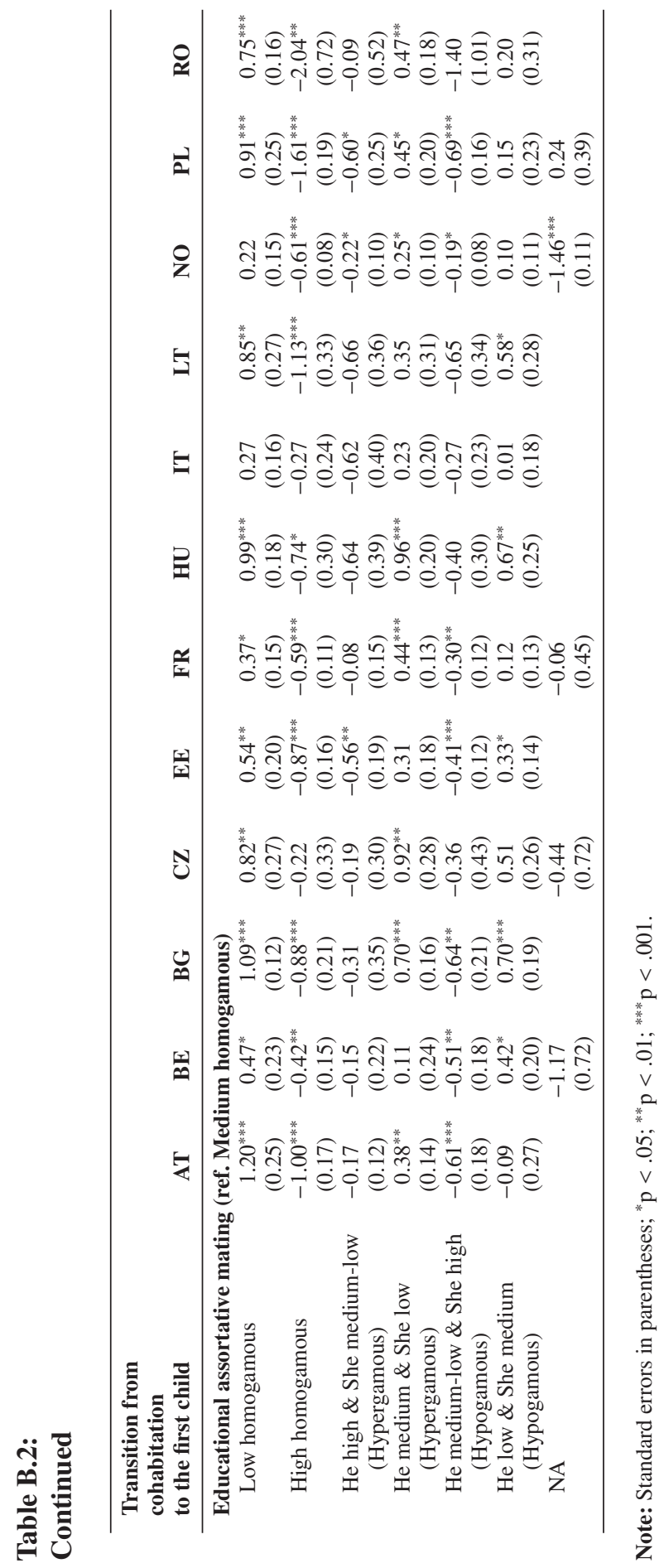




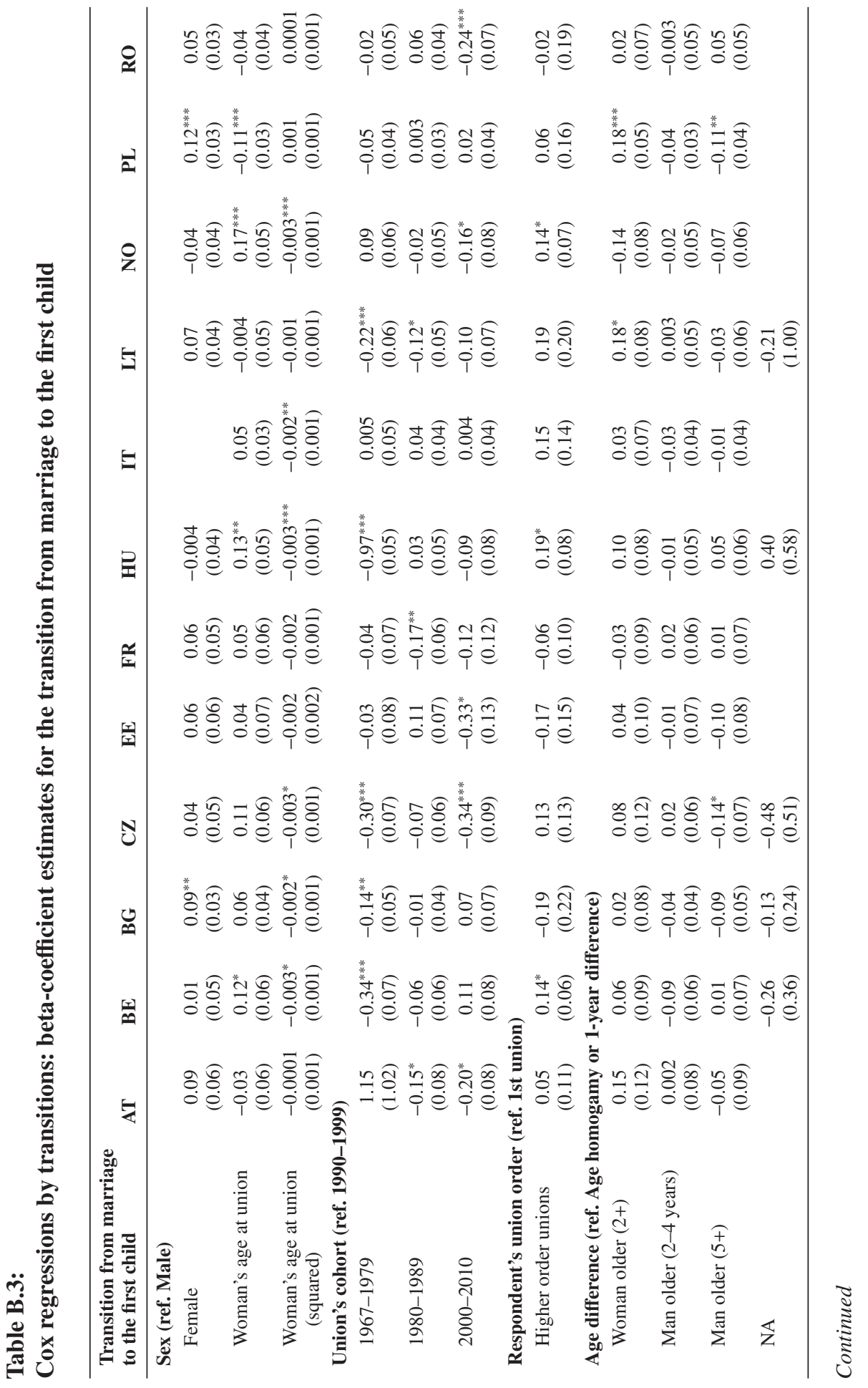




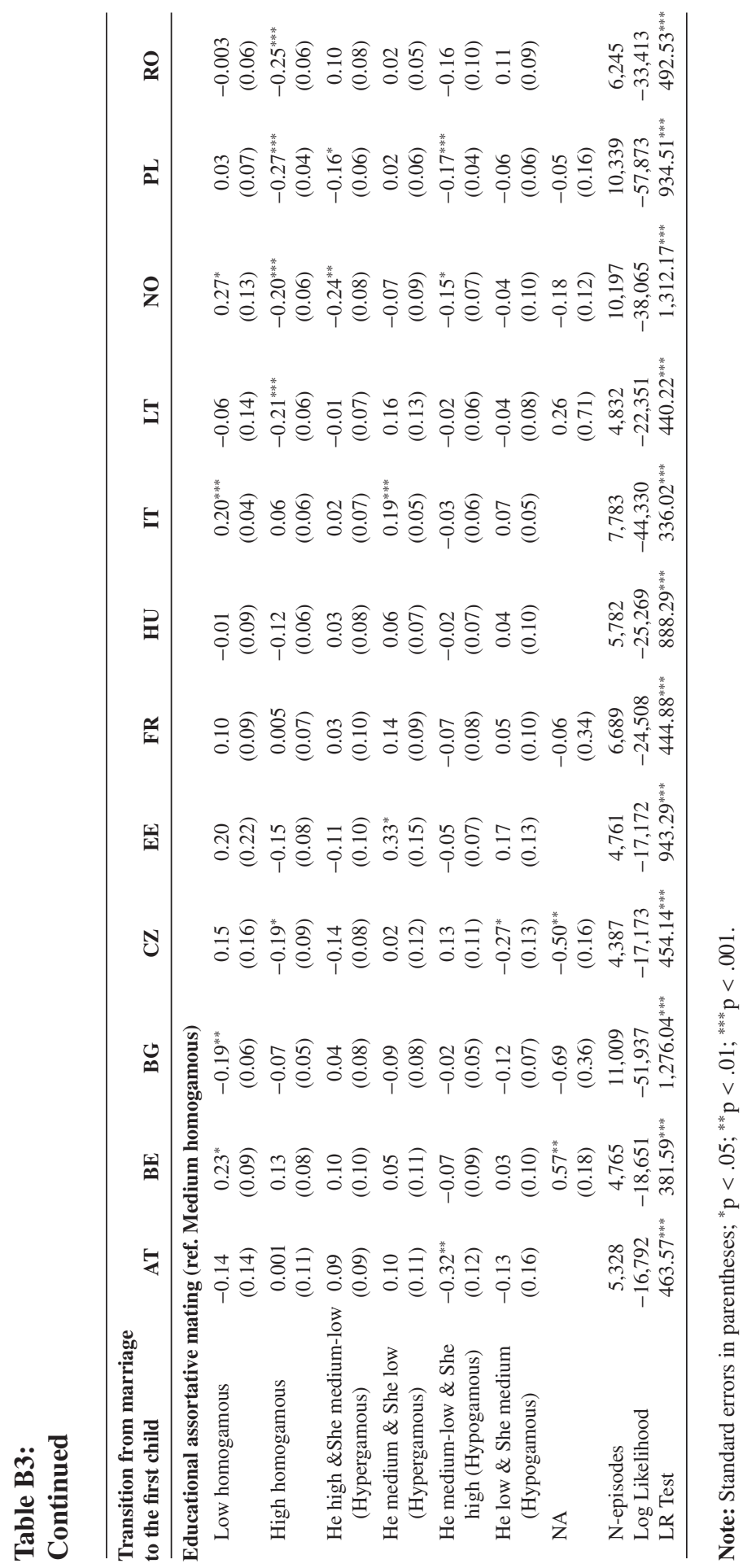




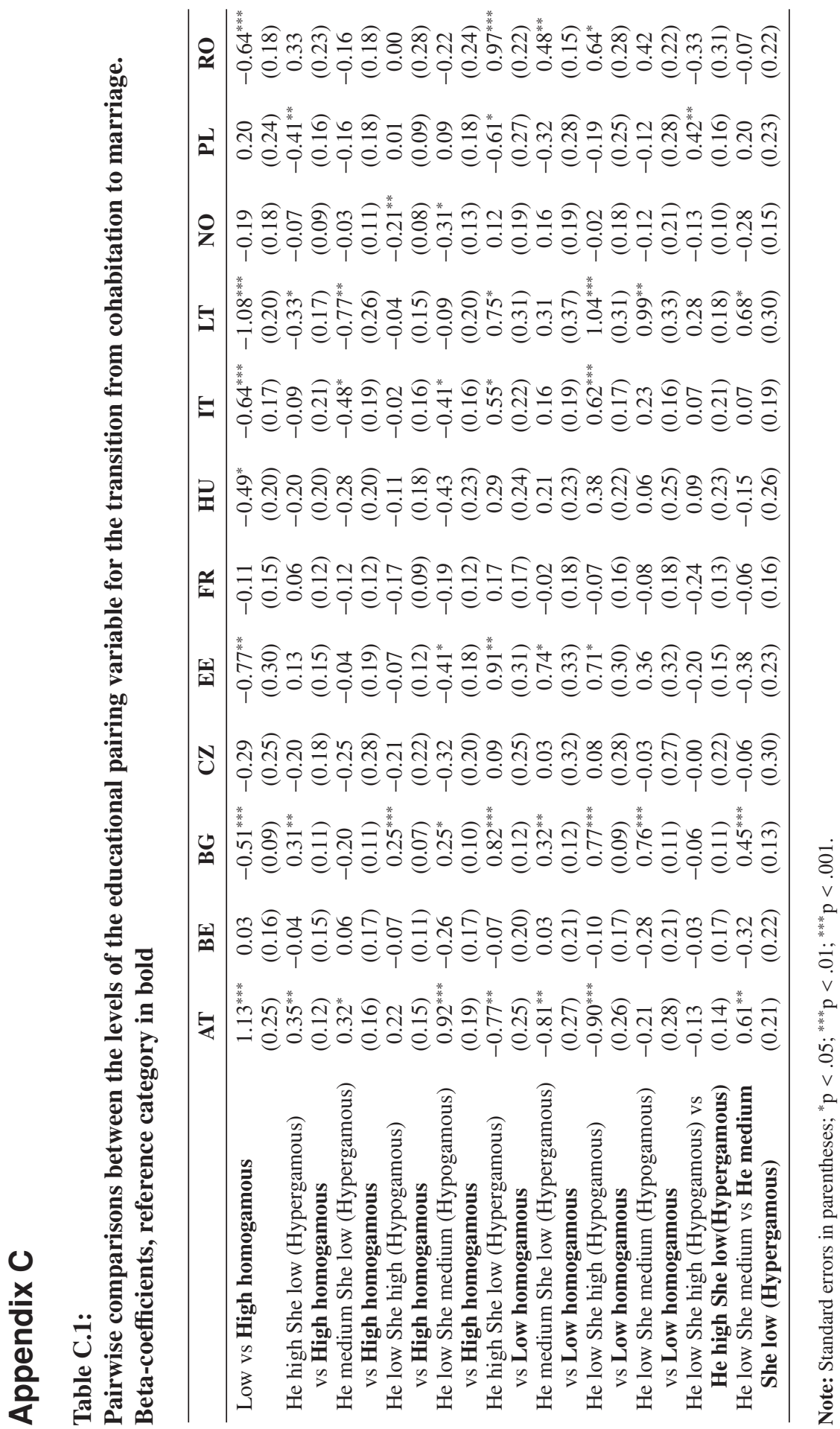




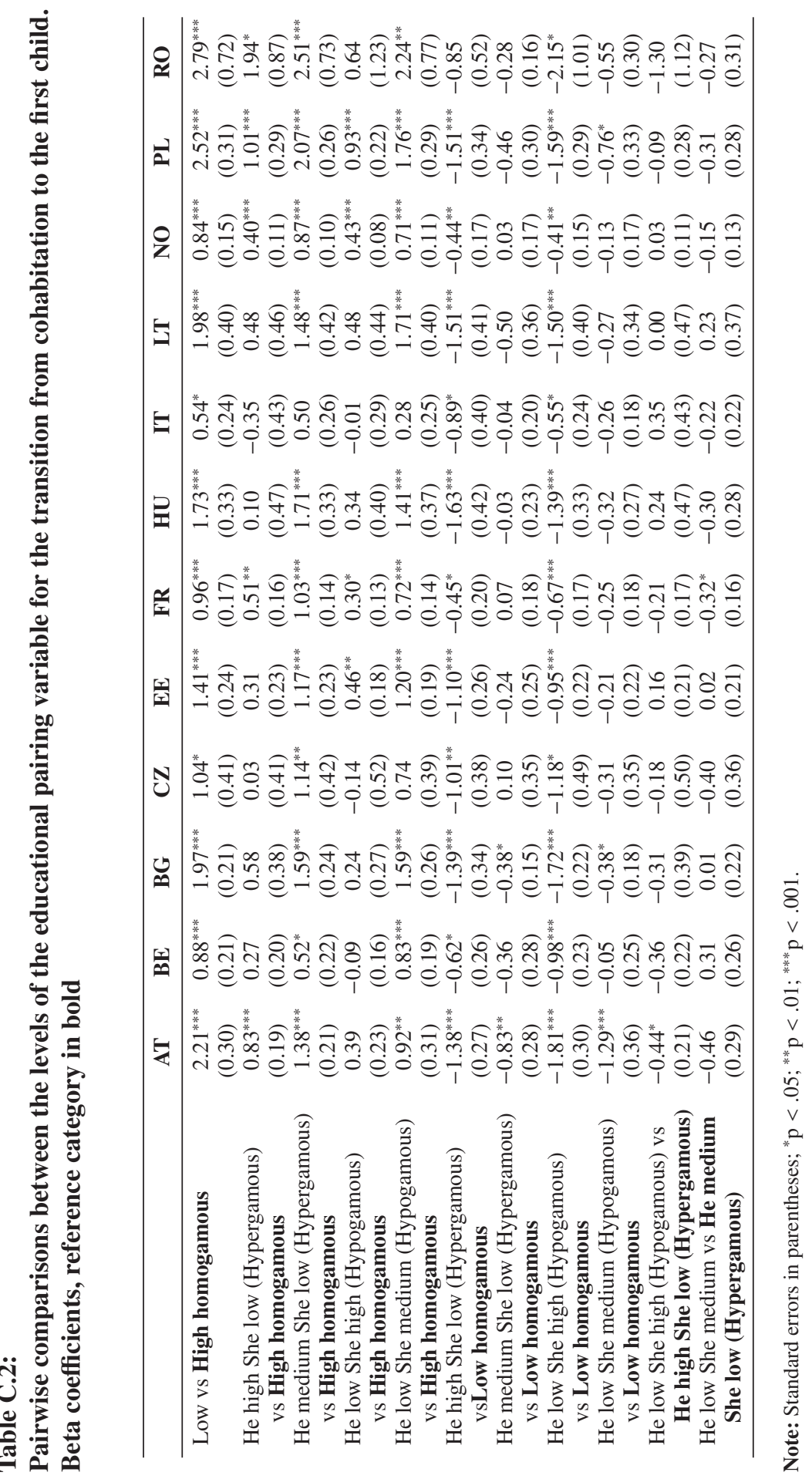




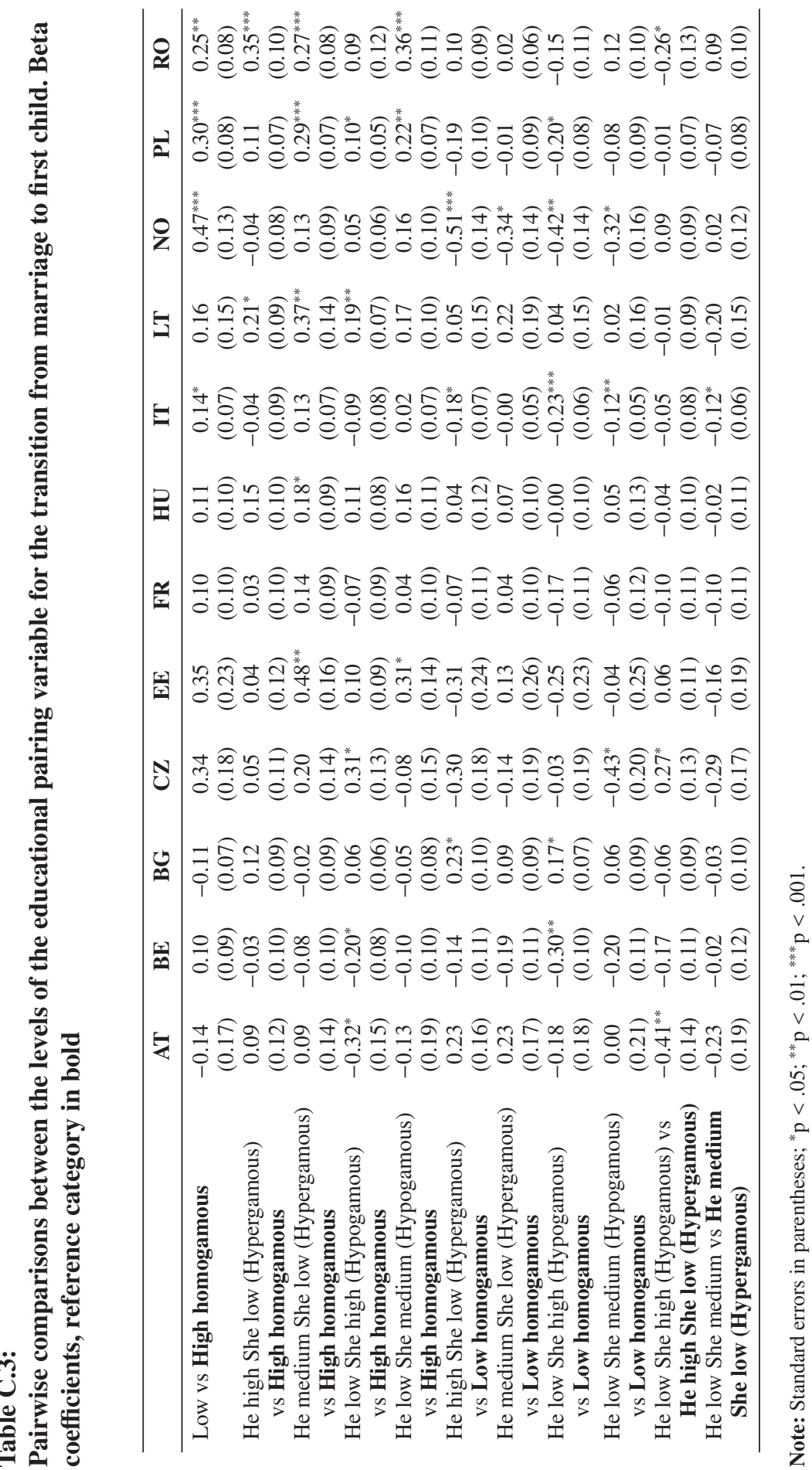


